Keyworth et al., 'The tuning of the energy levels of dibenzosilole copolymers....'

\title{
The tuning of the energy levels of dibenzosilole copolymers and applications in organic electronics
}

\author{
Colin W. Keyworth, ${ }^{a}$ Khai-Leok Chan, ${ }^{b}$ John G. Labram, ${ }^{a \#}$ Thomas D. Anthopoulos, ${ }^{a \#}$ \\ Scott E. Watkins, ${ }^{c}$ Mary McKiernan, ${ }^{d}$ Andrew J. P. White, ${ }^{a}$ Andrew B. Holmes, ${ }^{a, e}$ \\ Charlotte K. Williams ${ }^{*} a$
}

Received Xxx Xxxxxx 2010, Accepted Xxx Xxxxxx 2010

First published as an Advance Article on the web Xxx Xxxxxx 2010

\section{DOI: $\mathbf{x x} \cdot \mathbf{x x x x} / \mathbf{x x x x x x x x x x}$}

${ }^{a}$ Department of Chemistry; ${ }^{\text {a\# }}$ Department of Physics, Imperial College London, South Kensington, London, SW7 2AZ, UK. E-mail: c.k.williams@imperial.ac.uk; Fax: +4420 7594 5804; Tel: +4420 75945790

${ }^{b}$ Institue of Materials Research and Engineering (IMRE) and the Agency for Science, Technology and Research $(A * S T A R)$, Singapore 117602; Department of Chemistry, University of Cambridge, Lensfield Road, Cambridge, CB2 IEW, UK

${ }^{c}$ CSIRO Materials Science and Engineering, Bayview Avenue, Clayton, Victoria 3168, Australia

${ }^{d}$ Cambridge Display Technology Ltd, Greenwich House, Madingley Rise, Cambridge, CB3 OTX, UK

${ }^{e}$ Bio21 Institute, The University of Melbourne, 30 Flemington Rd, Parkville, Victoria 3010, Australia

An understanding of the structure-function relationships of conjugated polymers is an invaluable resource for the successful design of new materials for use in organic electronics. To this end, we report the synthesis, characterisation and optoelectronic properties of a range of new alternating copolymers of dibenzosilole. Suzuki polycondensation reactions were used to afford a series of eight conjugated materials, by the respective combination of either a 3,6- or 2,7-linked 9,9-dioctyldibenzosilole with 3,6-dibromo- $N$-octylcarbazole, triarylamine, oxadiazole and triazole monomers. The copolymers were fully characterised, using ${ }^{1} \mathrm{H}$, ${ }^{13} \mathrm{C}\left\{{ }^{1} \mathrm{H}\right\}$ NMR spectroscopy, size exclusion chromatography (SEC), differential scanning calorimetry (DSC) and thermogravimetric analysis (TGA). The photophysical properties were determined using UV-Vis spectroscopy, photoluminescence (PL) measurements, cyclic voltammetry (CV) and photoelectron emission spectroscopy in air (PESA). The spectroscopic and electrochemical measurements were used to determine the materials' 
Keyworth et al., 'The tuning of the energy levels of dibenzosilole copolymers....'

HOMO and LUMO energies and the values were correlated with the copolymer composition and structure. A selection of the copolymers (P4, P5 and P8) were evaluated as the active layer within single-layer polymer light emitting diodes (PLEDs), with the configuration: glass/ITO/PEDOT:PSS/emissive layer/Ba/Al, which gave low intensity electroluminescence. The selected copolymers were also evaluated as the organic semiconductor in bottom-gate, bottom-contact organic field effect transistors (OFETs). The best performing devices gave a maximum mobility of $3 \times 10^{-4} \mathrm{~cm}^{2} \mathrm{~V}^{-1} \mathrm{~s}^{-1}$ and current on/off ratios of $10^{5}$.

\section{Introduction}

Ever since the first reports of a conjugated polymer as the active layer in a light emitting diode (PLED), ${ }^{1}$ the potential to use polymers to replace conventional inorganic silicon-based electronics has attracted significant attention..$^{2-12}$ Conjugated polymers are now also applied in field effect transistors (FETs), ${ }^{13-14}$ photovoltaics (PV) ${ }^{15}$ and chemical sensors. ${ }^{16}$ The first commercially available small molecule (O)LEDs are now found in several small-display applications, such as mobile phones and MP3 players. They offer several desirable attributes, such as high resolution and high contrast images, with fast response times and wide viewing angles. In addition to these properties, PLED technology promises to deliver flexible, low cost and ink-jet printable large area displays. There is still much scope for improvement in the performance of materials for organic electronic applications; in particular, some device stabilities and lifetimes are low. ${ }^{17-18}$ It is therefore important that both the semiconducting materials and the understanding of their structure-property relationships continue to be improved.

Within the PLED arena, dialkyl-substituted polyfluorenes are the work-horse materials, due to their efficient blue electroluminescence, high charge carrier mobility and good processability. Fluorene-based moieties are also amenable to a wide range of coupling 
Keyworth et al., 'The tuning of the energy levels of dibenzosilole copolymers....'

chemistries and are often used as building blocks. However, the rapid loss of intensity in blue emission, coupled with the appearance of emission bands at lower energies (originating from keto-defect formation at the bridgehead position) during device operation, ${ }^{17-20}$ has led to a significant research effort to replace the bridgehead carbon with a heteroatom.

The use of heteroaromatic repeat units in conjugated polymers has proved successful for controlling both the polymer energy levels and the stability of the resulting electronic devices. $^{6,8-10,21}$ Silicon is an attractive choice, as its tetravalency allows the introduction of two solubilising substituents per repeat unit, while studies of siloles have shown the potential for enhanced electron transport. ${ }^{22-23}$ Density functional theoretical studies of the silole frontier molecular orbitals indicated an interaction between the butadiene $\pi^{*}$ orbital and the silylene $\sigma^{*}$ orbital, $^{22}$ which predicts the lowered LUMO levels observed in silole systems. In 2005, our research group reported the synthesis of poly(9,9-dioctyl-2,7-dibenzosilole) and its efficient and stable blue electroluminescence. ${ }^{24}$ The LUMO energy of this material was lowered by approximately $0.1 \mathrm{eV}$ in comparison with poly(9,9-dioctylfluorene). The enhanced thermal stability compared with poly(9,9-dioctyl-2,7-fluorene) was particularly attractive as the latter material is known to undergo degradation under device operating conditions, leading to blue-green emission. Recently, dibenzosilole-containing materials have been used in several applications including OPV, ${ }^{25-26}$ OFET $^{27-28}$ and even as sensors for explosive particulates. ${ }^{16,29-30}$

In 2005 both our group and that of Cao synthesised poly(9,9-dialkyl-3,6-dibenzosilole) homo-polymers. ${ }^{31-32}$ The material reported by Cao and co-workers was formed by a nickelcatalysed coupling reaction and was noted to possess a wide HOMO-LUMO gap of approximately $4.0 \mathrm{eV}^{32}$ Our group prepared an end-capped poly(9,9-dialkyl-3,6dibenzosilole) homo-polymer, via a Suzuki polycondensation, which was highly soluble in common organic solvents. ${ }^{31}$ The high energy gap of this material (calculated to be $3.5 \mathrm{eV}$ ), 
Keyworth et al., 'The tuning of the energy levels of dibenzosilole copolymers....'

was put to use as a host material for a phosphorescent iridium guest complex. The resulting blend was used as the active layer within a green emitting PLED device which displayed efficient electrophosphorescence with a low turn-on voltage (4 V) and complete energy transfer to the guest complex.

A statistical copolymer containing 10\% 9,9-dialkyl-3,6-dibenzosilole and 90\% 9,9-dialkyl2,7-fluorene subunits gave pure blue emission, a high external efficiency (3.34\%) and reasonably low turn-on voltage of $6.7 \mathrm{~V}^{33}$ A range of copolymers, incorporating 9,9-dialkyl3,6-dibenzosilole, were recently published by Mo et al., from which PLED devices were prepared. The devices gave predominantly blue or blue/green emission, with external quantum efficiencies of up to $3.17 \% .^{34}$

A recent paper by $\mathrm{Xu}$ and $\mathrm{Li}$ used a dibenzosilole core in some highly emissive trimetric materials, featuring a methoxy-substituted dibenzosilole core connected via ethyne linkages to a phenyl end group. ${ }^{35}$ Devices were not fabricated with the dibenzosiloles, but all three materials exhibited blue fluorescence with high fluorescence quantum yields (between 0.75 and 0.89).

Marks and co-workers have reported the use of two copolymers of 9,9'-dialkyl-2,7dibenzosilole and thiophene subunits for OFET applications. One material was an alternating copolymer, while the other contained two thiophene moieties within the repeat unit. Both materials showed excellent stability, but low hole mobility values within an OFET device. Within OTFT devices, both copolymers were found to be $p$-channel materials; the alternating copolymer showed a moderate hole mobility, while the material containing a higher proportion of thiophene showed a high mobility of $6.0 \times 10^{-3} \mathrm{~cm}^{2} \mathrm{~V}^{-1} \mathrm{~s}^{-1} \cdot{ }^{27-28}$

Cao and co-workers have recently reported OPV devices with power conversion efficiencies of up to $3.15 \%$, using a blend of $\mathrm{PC}_{71} \mathrm{BM}$ with two copolymers of 9,9'-dioctyl2,7-dibenzosilole and triarlylamine subunit, with different pendant groups attached. ${ }^{36}$ Yang 
Keyworth et al., 'The tuning of the energy levels of dibenzosilole copolymers....'

and co-workers have achieved remarkable power conversion efficiencies (up to $5.1 \%$ ) in OPV devices using $\mathrm{PC}_{70} \mathrm{BM}$ blends of polymers and copolymers of dithieno[3,2-b:2', '3'd] silole, a close analogue of dibenzosilole. ${ }^{37-38}$ Examples of dithienosiloles have also been reported as materials for OFETs ${ }^{28}$ and OLEDs. ${ }^{39}$

These successes highlight the promise of silicon-containing heteroaromatics for electronic applications. We were therefore interested in further investigation of the properties of various dibenzosilole-containing copolymers. Here we wish to report the preparation of a series of 2,7- and 3,6-linked dibenzosilole alternating copolymers. The influences of the linkage site of the dibenzosilole and the nature of the co-monomer on the copolymer's frontier orbital energies were investigated. Manipulation of the energy levels of these materials in a predictable manner is possible by the judicious choice of both co-monomer and linkage sites of the dibenzosilole repeat unit. The copolymers which were evaluated showed potential for use in PLED/OFET devices.

\section{Results and Discussion}

A series of eight copolymers was synthesised, four using the 3,6-linked dibenzosilole monomer $\mathbf{1}$ and four using the 2,7-linked dibenzosilole monomer $\mathbf{2}$ (See Figure 1). Oxadiazole and triazole monomers were selected to facilitate electron-transport, ${ }^{40,41}$ whilst carbazole and triarylamine monomers were selected to improve hole-transport. ${ }^{42-44}$ 
Keyworth et al., 'The tuning of the energy levels of dibenzosilole copolymers....'
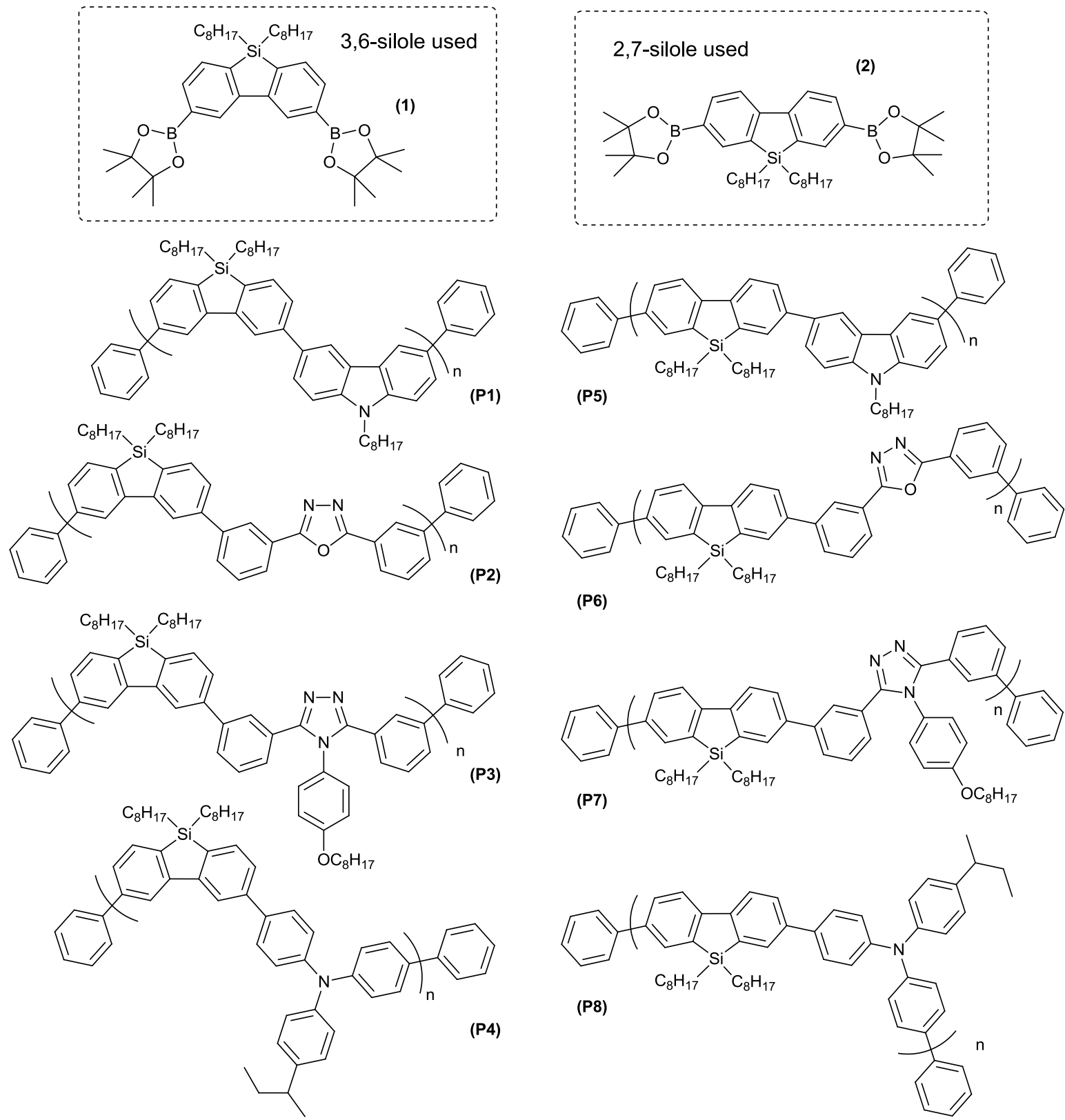

(P6)

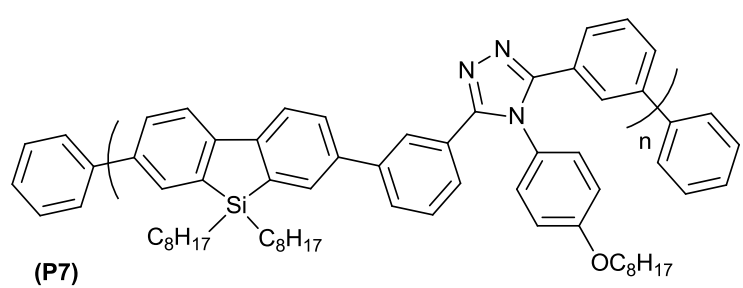

Figure 1 Dibenzosilole copolymers, arranged by dibenzosilole linkage positions.

\section{Monomer Syntheses}

The co-monomers 3,6-bis(4,4,5,5-tetramethyl-1,3,2-dioxaborolane-2-yl)-9,9-dioctyldibenzosilole (1) and 3,6-dibromo- $N$-octylcarbazole, were synthesised following literature routes. ${ }^{31,45}$ Synthesis of 2,7-bis(4,4,5,5-tetramethyl-1,3,2-dioxaborolane-2-yl)-9,9-dioctyldibenzosilole (2) was performed following a modification to the previously published route which enabled higher yields (two-fold increase) and facilitated scale-up (Scheme 1). ${ }^{24}$ The Ullmann coupling of commercially available 2,5-dibromonitrobenzene produced the biphenyl $\mathbf{3}$ in 
Keyworth et al., 'The tuning of the energy levels of dibenzosilole copolymers....'

79\% yield. Compound 3 was reduced, with tin powder and $\mathrm{HCl}$, to afford the diamine $\mathbf{4}$, in 92\% yield. Classical diazotization conditions, followed by Sandmeyer reaction $(\mathrm{HCl}$, $\mathrm{NaNO}_{2}, \mathrm{KI}$ ) afforded the diiodide 5, in 58\% yield; a significant improvement on the $30 \%$ previously reported. ${ }^{24}$ The formation of the dibenzosilole $\mathbf{6}$ from the diiodide 5 proceeded via a selective double halogen-lithium exchange, carried out at $-90{ }^{\circ} \mathrm{C}$ to ensure selectivity for the iodine substituents. The dilithiated intermediate was treated with di- $n$ octyldichlorosilane to afford the dibenzosilole $\mathbf{6}$, in $81 \%$ yield. The borylation of $\mathbf{6}$, using $t$ BuLi and 2-isopropoxy-4,4,5,5-tetramethyl-1,3,2-dioxaboralane, enabled the isolation of monomer 2 , in $57 \%$ yield.

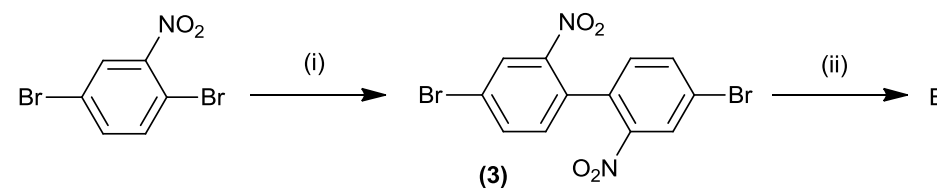

(v)

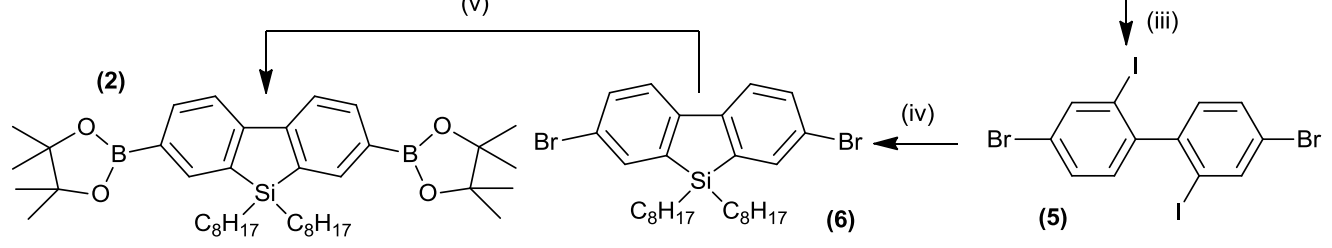

Scheme 1 Synthesis of 2,7-bis(4,4,5,5-tetramethyl-1,3,2-dioxaborolane-2-yl)-9,9-dioctyldibenzosilole (2). [Reagents and conditions: (i) $\mathrm{Cu}, \mathrm{DMF}, 125{ }^{\circ} \mathrm{C}, 3 \mathrm{~h}, 79 \%$; (ii) $\mathrm{Sn}, \mathrm{HCl}$, EtOH, $100{ }^{\circ} \mathrm{C}, 2 \mathrm{~h}, 92 \%$; (iii) $\mathrm{HCl}$, $\mathrm{NaNO}_{2}, \mathrm{MeCN}, \mathrm{H}_{2} \mathrm{O},-10$ to $-5{ }^{\circ} \mathrm{C}, 1 \mathrm{~h}$ then $\mathrm{KI} 60{ }^{\circ} \mathrm{C}, 16 \mathrm{~h}, 58 \%$; (iv) t-BuLi, $\mathrm{Si}\left(\mathrm{C}_{8} \mathrm{H}_{17}\right){ }_{2} \mathrm{Cl}_{2},-90{ }^{\circ} \mathrm{C}, 81 \%$; (v) tBuLi, 2-isopropoxy-4,4,5,5-tetramethyl-1,3,2-dioxaboralane, $-78{ }^{\circ} \mathrm{C}, 57 \%$ ]

The synthesis of the triarylamine monomer 7 was achieved in a one-step process, utilising a ligand-catalysed Ullmann condensation. ${ }^{46-47}$ 1,10-Phenanthroline monohydrate and copper chloride were used as the catalyst system to couple one equivalent of 4-sec-butylaniline with two equivalents of 4-bromoiodobenzene. The triarylamine 7 was recovered, after extensive purification by column chromatography and recrystallisation, in 33\% yield (Scheme 2).

The monomers 2,5-bis(3-bromophenyl)1,3,4-oxadiazole (9) and 3,5-bis(3-bromophenyl)4-(4-(octyloxy)phenyl)1,2,4-triazole (11) were prepared by the condensation of 3- 
Keyworth et al., 'The tuning of the energy levels of dibenzosilole copolymers....'

bromobenzoyl chloride with hydrazine monohydrate to afford the hydrazine intermediate $\mathbf{8}$, in $78 \%$ yield. Treatment of $\mathbf{8}$ with phosphorous oxychloride gave oxadiazole $\mathbf{9}$, in $88 \%$ yield. Treatment of $\mathbf{8}$ with phosphorous pentachloride, in toluene, afforded the hydrazine 10, in $18 \%$ yield. The yield was low due to formation of a large proportion of oxadiazole 9 byproduct (approx. 1:3 ratio of oxadiazole : hydrazine), as reported in a 1906 study. ${ }^{48}$ The reaction of 10 with 4-octyloxyaniline in $N, N$-dimethylaniline, followed by treatment with $\mathrm{HCl}$, afforded monomer 11, in 66\% yield (Scheme 3). The crystal structures of $\mathbf{7}$ and $\mathbf{1 1}$ were obtained by single crystal X-ray diffraction (Details included in ESI).

2<smiles>Brc1ccc(I)cc1</smiles><smiles>CCC(C)c1ccc(N)cc1</smiles>

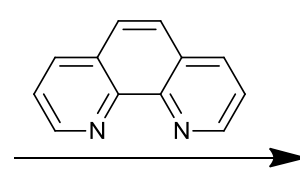

(i)<smiles>CCC(C)c1ccc(N(c2ccc(Br)cc2)c2ccc(Br)cc2)cc1</smiles>

Scheme 2 Ligand-catalysed Ullmann coupling to form $N, N$-bis(4-bromobenzene)-4-secbutylaniline (7). ${ }^{46-47}$ [Reagents and conditions: (i) $\mathrm{CuCl}, 1,10$-phenanthroline monohydrate, $\mathrm{KOH}$, toluene, reflux $16 \mathrm{~h}, \mathrm{~N}_{2}, 33 \%$ ]<smiles>CCOc1ccc(-n2c(-c3cccc(Br)c3)nnc2-c2cccc(Br)c2)cc1</smiles>

Scheme 3 Synthesis of 2,5-bis(3-bromophenyl)1,3,4-oxadiazole (9) and 3,5-bis(3-bromophenyl)-4-(4(octyloxy)phenyl)1,2,4-triazole (11).

[Reagents and conditions: (i) $N$-methyl-2-pyrrolidinone, $\mathrm{N}_{2} \mathrm{H}_{4} \cdot \mathrm{H}_{2} \mathrm{O}, 0{ }^{\circ} \mathrm{C}$ to RT $16 \mathrm{~h}, \mathrm{~N}_{2}, 78 \%$; (ii) $\mathrm{POCl}_{3}$, $130^{\circ} \mathrm{C}, 7 \mathrm{~h}, \mathrm{~N}_{2}, 88 \%$; (iii) $\mathrm{PCl}_{5}$, toluene, reflux, $16 \mathrm{~h}, 18 \%$; (iv) $\mathrm{N}, \mathrm{N}$-dimethylaniline, $135^{\circ} \mathrm{C}, 48 \mathrm{~h}, 66 \%$ ]

\section{Copolymer Syntheses}


Keyworth et al., 'The tuning of the energy levels of dibenzosilole copolymers....'

Suzuki polycondensation reactions were used to prepare the eight alternating copolymers

(Figure 1). For each copolymerisation, reaction conditions were identical; the two monomers were added in a 1:1 molar ratio; $\mathrm{Pd}(\mathrm{OAc})_{2}$ and tricyclohexylphosphonium tetrafluoroborate were used as the pro-catalyst and pro-ligand respectively; a biphasic mixture of toluene and aqueous tetraethylammonium hydroxide was stirred, vigorously under nitrogen, at $110{ }^{\circ} \mathrm{C}$ (Scheme 4). End-capping was achieved by addition of further catalyst/ligand, firstly with bromobenzene and finally with phenylboronic acid, in a 1:2 molar ratio. After filtration through silica, the organic layer was concentrated and precipitated by addition of methanol, filtered and collected. The solid was then re-dissolved in dichloromethane and the precipitation/filtration process was repeated.

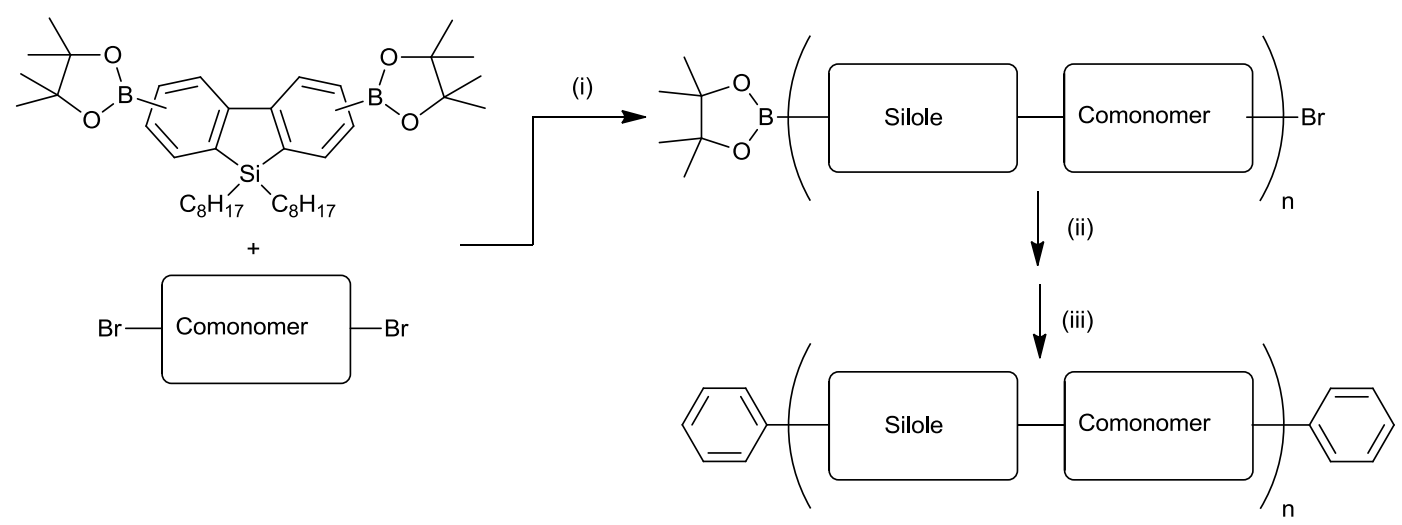

Scheme 4 General reaction scheme for Suzuki polycondensations.

[Reagents and conditions: (i) $2 \mathrm{~mol} \% \mathrm{Pd}(\mathrm{OAc})_{2}, 8 \mathrm{~mol} \%\left[\left(\mathrm{C}_{6} \mathrm{H}_{11}\right)_{3} \mathrm{PH}\right] \mathrm{BF}_{4}, 20 \%$ aq. $\left(\mathrm{C}_{2} \mathrm{H}_{5}\right)_{4} \mathrm{NOH}, 110{ }^{\circ} \mathrm{C}, 48$ $\mathrm{h}$; (ii) bromobenzene, $2 \mathrm{~mol} \% \mathrm{Pd}(\mathrm{OAc})_{2}, 8 \mathrm{~mol} \%\left[\left(\mathrm{C}_{6} \mathrm{H}_{11}\right)_{3} \mathrm{PH}\right] \mathrm{BF}_{4}, 110{ }^{\circ} \mathrm{C}, 16 \mathrm{~h}$; (iii) phenyboronic acid, 2 $\left.\mathrm{mol} \% \mathrm{Pd}(\mathrm{OAc})_{2}, 8 \mathrm{~mol} \%\left[\left(\mathrm{C}_{6} \mathrm{H}_{11}\right)_{3} \mathrm{PH}\right] \mathrm{BF}_{4}, 110{ }^{\circ} \mathrm{C}, 16 \mathrm{~h}\right]$

Some of the properties of the copolymers are summarised in Table 1. The isolated yields were all reasonably high, ranging from $88 \%$ to $96 \%$, showing that the copolymers were not significantly fractionated during work-up. However, the molecular weights were universally low, particularly for copolymers containing the oxadiazole and carbazole monomers, with no increase observed for longer reaction times, using these conditions. The molecular weight 
Keyworth et al., 'The tuning of the energy levels of dibenzosilole copolymers....'

may, therefore, be solubility-limited. The polydispersity indices (PDI), determined by GPC were quite narrow for all samples, probably due to the low molecular weights.

Copolymers P6, P1, P3 and P4 exhibited bimodal (and even trimodal) molecular weight distributions by GPC (Table 1 lists the $\mathrm{M}_{w-\max }$, the complete distributions are illustrated in the ESI (Figures S8-S15)). The cause of this has not been confirmed, but could be due to the relatively low degrees of polymerisation, poor solubility of the copolymers in the GPC mobile phase (THF), or the formation of macrocycles. The glass transition temperatures, as measured by DSC, ranged from $67-111^{\circ} \mathrm{C}$. This is comparable to the reported $\mathrm{T}_{\mathrm{g}}$ values for poly(3,6-dibenzosilole-co-2,7-fluorene)-based copolymers $\left(c f .58{ }^{\circ} \mathrm{C}<\mathrm{T}_{\mathrm{g}}<80^{\circ} \mathrm{C}\right) .{ }^{33}$ The decomposition temperatures, which were taken as the temperature at which a $5 \%$ mass loss occurred, were measured by thermogravimetric analysis and were between $320-380{ }^{\circ} \mathrm{C}$, apart from P5, which decomposed at $185^{\circ} \mathrm{C}$.

Table 1 Physical properties of copolymers P1-P8.

\begin{tabular}{|c|c|c|c|c|c|c|c|c|}
\hline Copolymer & P1 & P2 & P3 & P4 & P5 & P6 & P7 & P8 \\
\hline Dibenzosilole & 1 & 1 & 1 & 1 & 2 & 2 & 2 & 2 \\
\hline Co-monomer & $\mathrm{CBZ}$ & 9 & 11 & 7 & CBZ & 9 & 11 & 7 \\
\hline Isolated Yield & $96 \%$ & $89 \%$ & $94 \%$ & $92 \%$ & $96 \%$ & $88 \%$ & $91 \%$ & $92 \%$ \\
\hline $\mathbf{C D C *} \quad M_{n}$ & 4800 & 3300 & 6900 & 8000 & 3400 & 4000 & 6700 & 5700 \\
\hline Data & 6600 & 5600 & 10500 & 10700 & 5500 & 4700 & 12200 & 11700 \\
\hline PDI & 1.38 & 1.7 & 1.52 & 1.34 & 1.61 & 1.19 & 1.82 & 2.05 \\
\hline $\mathrm{DSC}^{\dagger} \dagger \quad \mathbf{T}_{\mathrm{g}} /{ }^{\circ} \mathbf{C}$ & 76 & 90 & 107 & 84 & 87 & 67 & 111 & 90 \\
\hline TGA $\neq \quad \mathbf{T}_{\mathrm{d}} /{ }^{\circ} \mathbf{C}$ & 343 & 380 & 363 & 328 & 185 & 347 & 332 & 353 \\
\hline
\end{tabular}

* GPC measurements were carried out in THF using narrow molecular weight polystyrene standards as the calibrant; $\uparrow$ DSC analyses were conducted at a scan rate of $40{ }^{\circ} \mathrm{C} / \mathrm{min}$. In each case, three cycles were recorded and the average value is reported; $\$$ The decomposition temperature is reported as the temperature at which $5 \%$ weight loss occurred. This was determined using TGA at a scan rate of $10{ }^{\circ} \mathrm{C} / \mathrm{min}$; $\mathrm{CBZ}-3,6$-dibromo- $N$ octylcarbazole.

\section{Characterisation and Photophysical Measurements}


Keyworth et al., 'The tuning of the energy levels of dibenzosilole copolymers....'

The UV-Vis spectra of copolymers $\mathbf{P 1}$ to $\mathbf{P 8}$ were determined in chloroform solutions (Figure 2). All the materials absorbed in the UV-blue region of the electromagnetic spectrum, the absorption maxima $\left(\lambda_{\max }\right)$ and difference between the absorption maxima of the 3,6-and 2,7linked dibenzosiloles $(\Delta \lambda)$ are summarised in Table 2. The 3,6-linked copolymers (P1-4) showed absorption maxima and onset wavelengths which were hypsochromically shifted compared to the 2,7-linked copolymers (P5-8).

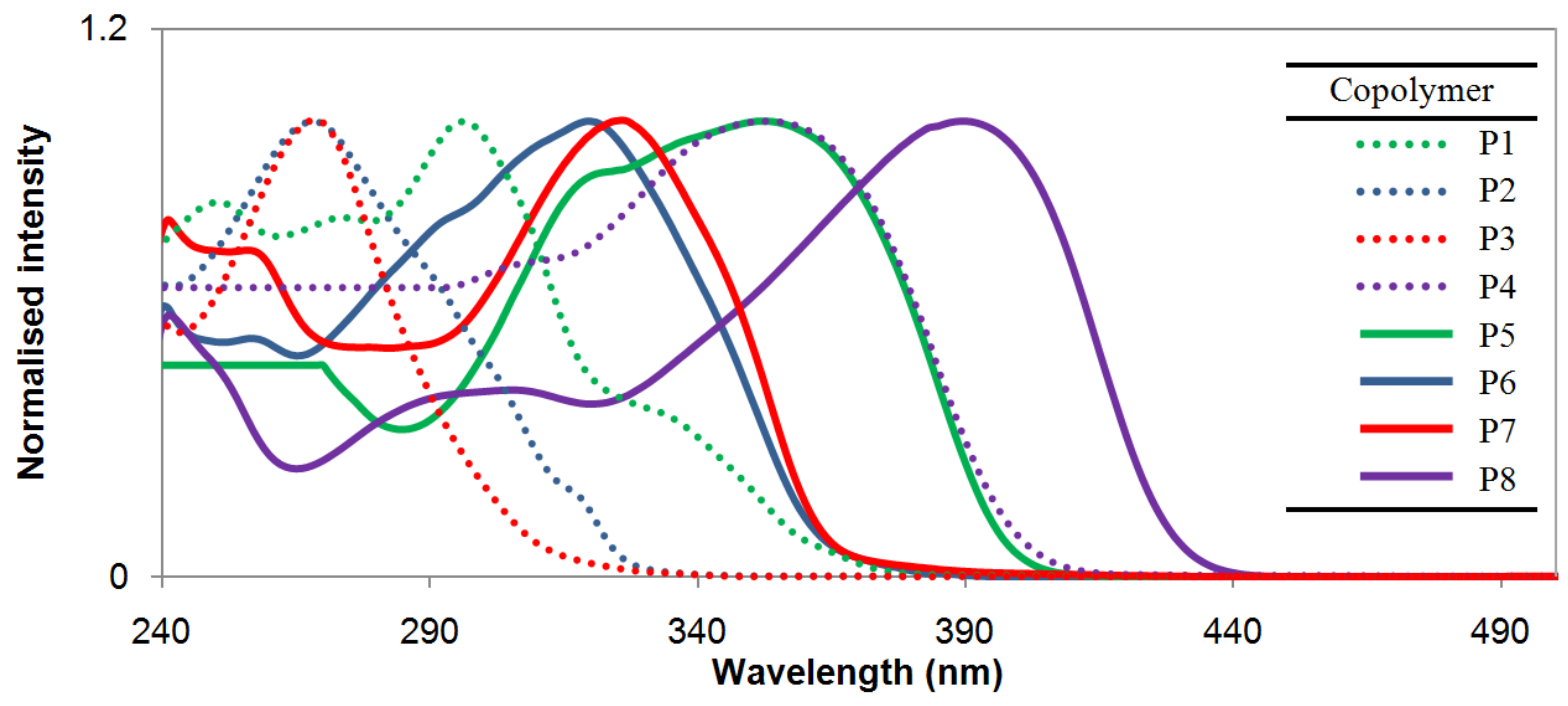

Figure $2 \mathrm{UV}$-Vis spectra of the copolymers, recorded in $\mathrm{CHCl}_{3}$ solution $\left(\sim 4 \times 10^{-5} \mathrm{~mol} \mathrm{dm}^{-3}\right)$ and intensitynormalised.

The optically determined HOMO-LUMO gap $\left(\mathrm{E}_{\mathrm{g}}\right)$ was calculated for each copolymer from the approximated onset wavelength of the absorption $(0 \rightarrow 0)$ band edge $\left(\lambda_{\text {onset }}\right)$. The values are summarised in Table 2, together with the difference in energy gap $\left(\Delta \mathrm{E}_{\mathrm{g}}\right)$ between the 3,6-linked dibenzosilole copolymers and their 2,7-linked counterparts (i.e. $\Delta \mathrm{E}_{\mathrm{g}}=\Delta \mathrm{E}_{\mathrm{g}(3,6)}$ - $\left.\Delta \mathrm{E}_{\mathrm{g}(2,7)}\right)$. The alternating copolymers of 3,6-dibenzosilole all showed higher energy gaps than the 2,7-substituted analogues, consistent with the previous findings for the two homopolymers. $^{24,31-32}$ Copolymers containing triarylamine (P4 and P8) and carbazole (P1 and P5) subunits have higher absorption onset wavelengths and consequently smaller energy gaps, implying a greater degree of conjugation within these materials. When considering the 
Keyworth et al., 'The tuning of the energy levels of dibenzosilole copolymers....'

difference in optical energy gap $\left(\Delta \mathrm{E}_{\mathrm{g}}\right)$, observed when the dibenzosilole is linked through '2,7'- or '3,6'-positions, the data shows an increase with co-monomer in the order: triarylamine $<$ carbazole $<$ oxadiazole < triazole. An average $\Delta \mathrm{E}_{\mathrm{g}}$ value of $37 \mathrm{~nm}(0.35 \mathrm{eV})$ is observed.

Table 2 Summary of UV-Vis absorption onset wavelengths of copolymers P1 to P8, along with calculated differences in wavelengths and bandgap energy.

\begin{tabular}{|c|c|c|c|c|c|}
\hline \multirow[b]{2}{*}{ Measurement } & \multirow[b]{2}{*}{ Co-monomer } & \multicolumn{2}{|c|}{ Wavelength $\lambda(\mathrm{nm})$} & \multirow[b]{2}{*}{$\begin{array}{c}\Delta \lambda \\
(\mathbf{n m})\end{array}$} & \multirow{2}{*}{$\begin{array}{l}\Delta \mathbf{E}_{\mathrm{g}} \\
(\mathrm{eV})\end{array}$} \\
\hline & & $\begin{array}{c}\text { 2,7-Dibenzosilole } \\
\left(\mathbf{E}_{\mathrm{g}} / \mathrm{eV}\right)\end{array}$ & $\begin{array}{c}\text { 3,6-Dibenzosilole } \\
\left(\mathbf{E}_{\mathrm{g}} / \mathrm{eV}\right)\end{array}$ & & \\
\hline $\mathrm{UV}-\mathrm{V}$ is & Triarylamine & P8: 390 & P4: 353 & 37 & - \\
\hline Absorption & Carbazole & P5: 353 & P1: 296 & 57 & - \\
\hline Maximum & Oxadiazole & P6: 320 & P2: 268 & 52 & - \\
\hline$\lambda_{\max }$ & Triazole & P7: 326 & P3: 268 & 58 & - \\
\hline \multirow{4}{*}{$\begin{array}{c}\text { UV-Vis } \\
\text { Onset } \\
\lambda_{\text {onset }}\end{array}$} & Triarylamine & P8: $428(2.90)$ & P4: $400(3.10)$ & 28 & 0.20 \\
\hline & Carbazole & P5: 398 (3.12) & P1: 366 (3.39) & 32 & 0.27 \\
\hline & Oxadiazole & P6: $364(3.41)$ & P2: 328 (3.78) & 36 & 0.37 \\
\hline & Triazole & P7: $364(3.41)$ & P3: 312 (3.97) & 52 & 0.56 \\
\hline
\end{tabular}

The differences in the energy gaps (and hence changes in effective conjugation) for the copolymers can be rationalised by considering the maximum number of conjugated paraphenylene units within each polymer backbone. Figure 3 shows a 'cartoon' depiction of a short chain of each of the eight copolymers, arranged by co-monomer and dibenzosilole monomer used. Maximum lengths of conjugation (through para-phenylene units) are highlighted in blue, while possible conjugation through other subunits is highlighted in purple.

Within the triarylamine-containing copolymers $\mathbf{P 4}$ and P8, overlap between the aryl $\pi$ system with the $p$-orbital of the nitrogen atom leads to a high degree of conjugation along both of these polymer backbones (highlighted in purple). In the case of $\mathbf{P 8}$, the length of conjugation is essentially 'non-limited' in theory (although in reality, steric interactions may 
Keyworth et al., 'The tuning of the energy levels of dibenzosilole copolymers....'

limit this conjugation length, by causing rotational distortions and diminishing the orbital overlap). The backbone of copolymer $\mathbf{P 4}$ contains meta-linkages however, which limit the possible length of conjugation to either 2 or 5 phenylene units (highlighted in blue). Since the change in orbital energy gap between these two systems is not particularly large, it can be inferred that the effective conjugation length in polymer $\mathbf{P 8}$ is therefore slightly longer than 5 phenylene units. The increased conjugation in these polymers leads to a decreased energy gap and an increased UV-Vis absorption onset wavelength (the highest amongst the eight copolymers).

When considering the carbazole-containing systems P1 and P5, some degree of conjugation is expected to exist (as with the triarylamines) between the aryl $\pi$-system and nitrogen $p$-orbital. ${ }^{45,49}$ Since the UV-Vis absorption onset wavelength of $\mathbf{P 5}$ is within $2 \mathrm{~nm}$ of that of copolymer P4, the effective conjugation of the (theoretically, non-limited) copolymer P5 must also be around 5 phenylene units. This indicates that the extent of conjugation through a 3,6-linked carbazole subunit is lower than that though a triarylamine subunit. Accordingly, the onset wavelengths are lower for carbazole-containing copolymers.

When considering the oxadiazole- and triazole-containing copolymers, it can be seen from Figure 3 that $\mathbf{P 6}$ and $\mathbf{P 7}$ both have maximum conjugation lengths of $3^{*}$ and 4 units (where $*$ denotes an unknown extent of conjugation over the triazole/oxadiazole 5-membered rings). The maximum conjugation length for both materials is therefore predicted to be the same 4unit stretch along the dibenzosilole subunit. This postulation is supported by identical UVVis onset wavelengths for each material, with a value of $364 \mathrm{~nm}$ (giving an energy gap of 3.41 eV). The 3,6-linked copolymers $\mathbf{P 2}$ and $\mathbf{P 3}$ do not have the same 4-unit maximum conjugation lengths, as the linkages are now 'meta'; the oxadiazole/triazole subunits must therefore be the maximum conjugation lengths ( $3 *$ units). Since the onset wavelength is 
Keyworth et al., 'The tuning of the energy levels of dibenzosilole copolymers....'

lower for $\mathbf{P 3}$ than for $\mathbf{P 2}$, it can be concluded that the oxadiazole subunit is more highly conjugated than the triazole subunit.

In general, the 3,6-linked dibenzosilole copolymers have lowered frontier orbital energy gaps, as a consequence of the diminished conjugation due to meta-linkages. The difference in energy gaps between the 2,7-linked and 3,6-linked systems, $\Delta \mathrm{E}_{\mathrm{g}}$, is smaller for the triarylamine and carbazole-containing materials because the interaction of phenylene $\pi$ orbitals with nitrogen $p$-orbitals leads to increased conjugation for both 2,7- and 3,6-linked systems.

Figure 3 Depiction of maximum conjugation lengths within copolymer backbones. 
Keyworth et al., 'The tuning of the energy levels of dibenzosilole copolymers....'

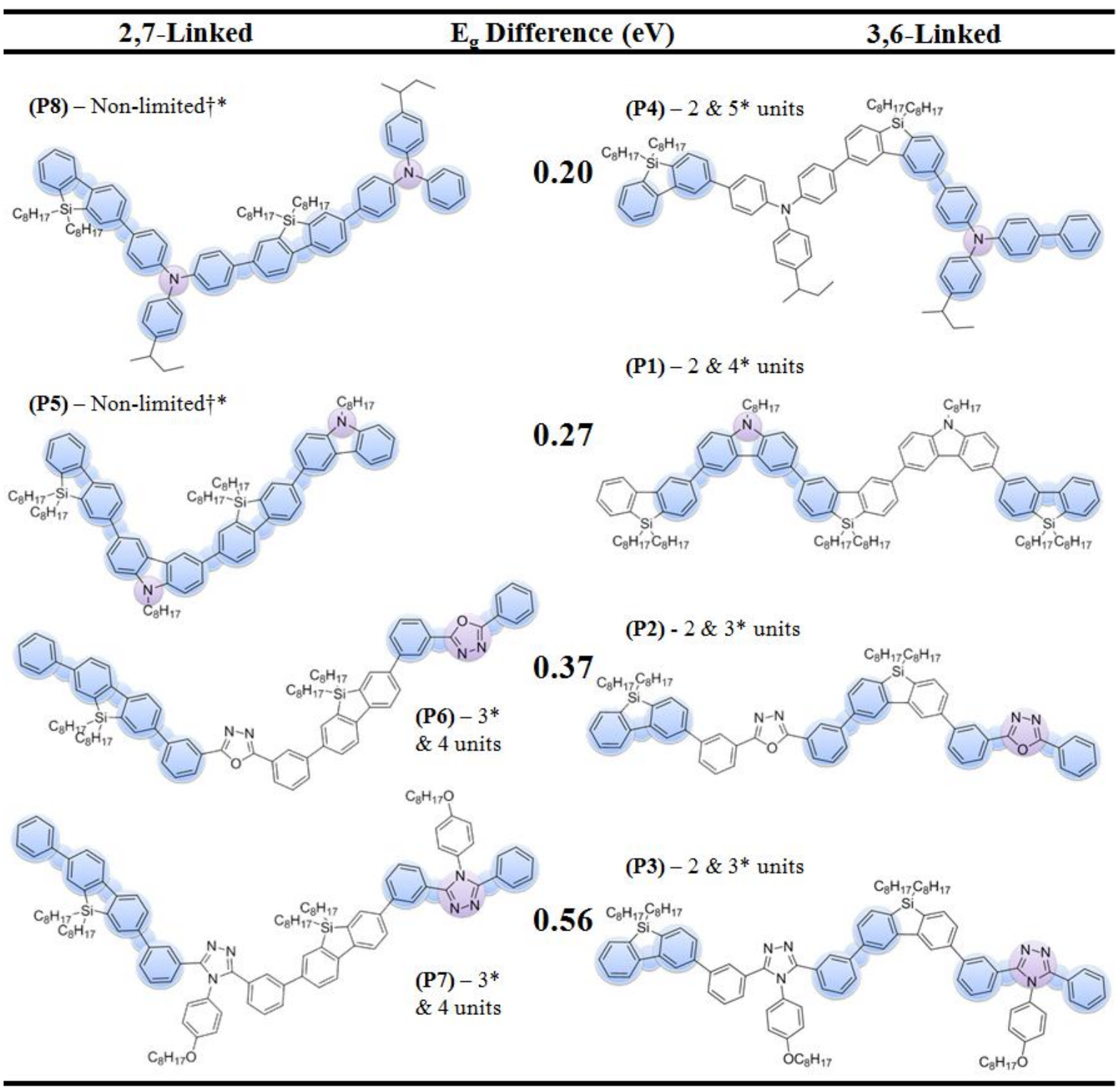

Note: $\uparrow$ May not be unlimited due to steric-induced distortional effects; * - denotes an extended conjugation, which may not have the same strength as a biphenyl subunit

\section{Photoluminescence Spectra and Cyclic Voltammetry}

The copolymers were spin-coated onto quartz plates and photoluminescence spectra of the eight thin films were measured, using the absorption maxima values, obtained by UV-Vis spectroscopy, as the excitation wavelength (Figure 4). The majority of spectra display multiple emission maxima, due to multiple electronic excitations. Most of the samples emit in the violet-blue region of the visible spectrum (the electromagnetic spectrum is shown at the top of the graph for reference), however, the emission maxima for copolymers P1, P2 and P3 
Keyworth et al., 'The tuning of the energy levels of dibenzosilole copolymers....'

lie within the UV region (with P1 and P2 having large shoulder peaks in the blue region). The CIE coordinates of the emission from the eight copolymers, in the thin-film state, were determined from the photoluminescence spectrum from each material and the results are tabulated within Figure 4. All the copolymers exhibited deep blue photoluminescence, in most cases close to the CIE coordinates for high definition blue LED devices $(0.15,0.06)$. Only materials P1, P5 and P8 do not give pure blue emission.

The emission spectra were also recorded in solution (chloroform). The majority of the spectra were very similar to the thin films, with the exception of $\mathbf{P 1}$ and $\mathbf{P 2}$. The appearance of lower energy emission bands in the solid state (thin film) are ascribed to aggregation effects (Figure 5). Both materials $\mathbf{P 1}$ and P2 show single emission maxima in solution (as did all of the copolymer samples) and these emission maxima coincide with the maxima present in the solid state.

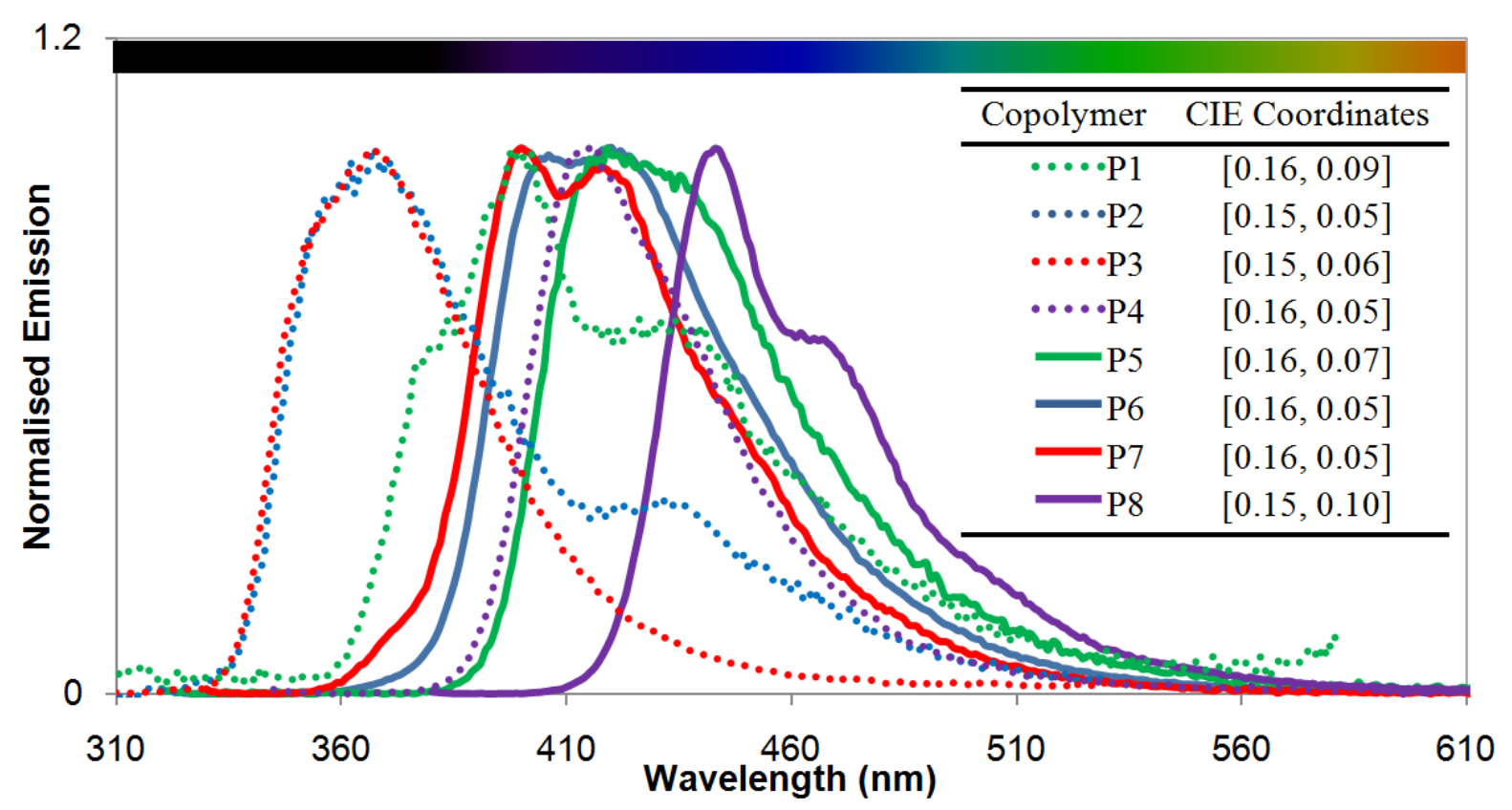

Figure 4 PL spectra and calculated CIE coordinates for the copolymer samples spin-coated on quartz plates. 


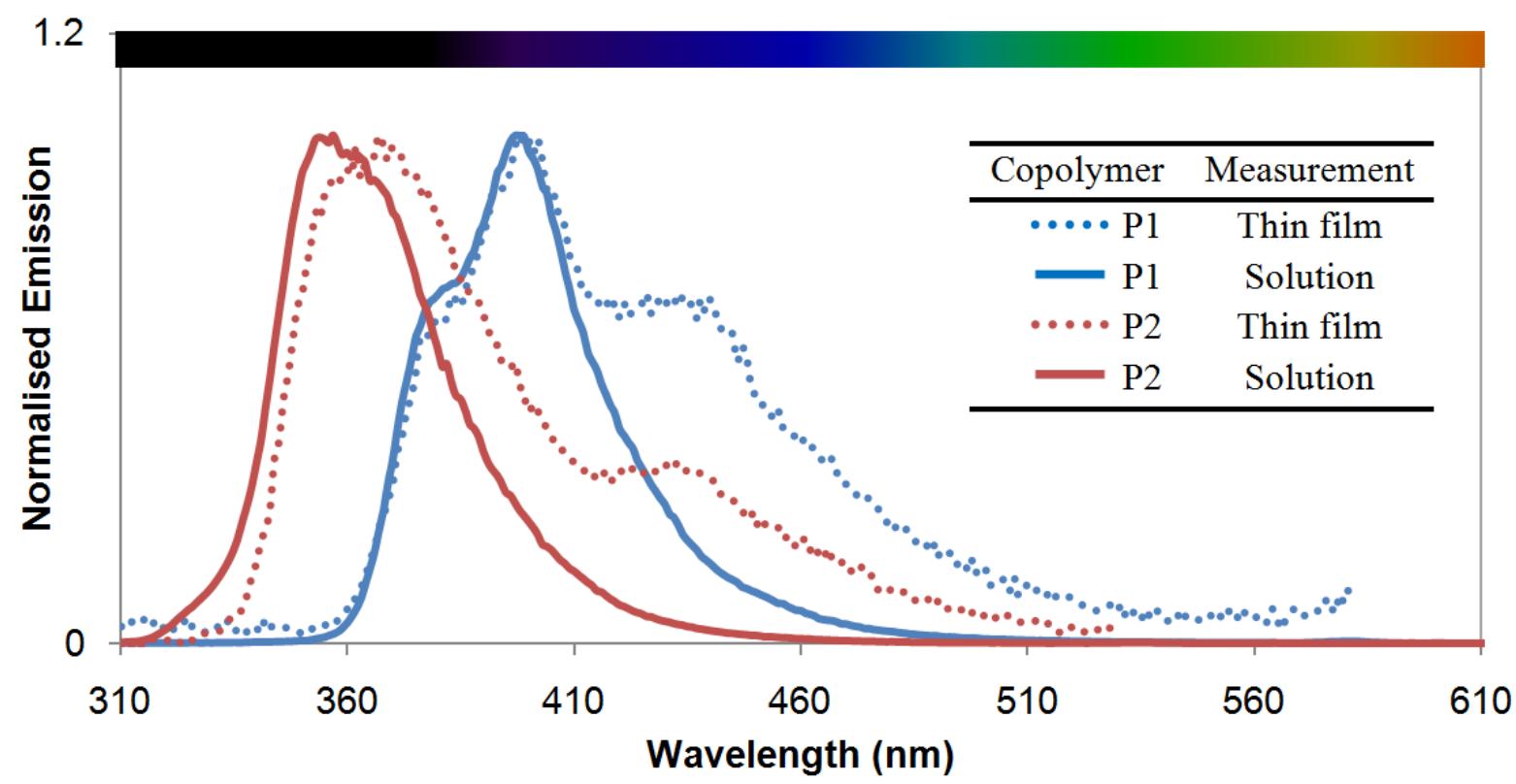

Figure 5 Comparative PL spectra of copolymers P1 and P2 in the solution and solid states.

Cyclic voltammetry was used to determine the frontier orbital energy levels for each copolymer (Table 3). The materials were spin-coated onto a glass-carbon working electrode and immersed, with a platinum wire counter electrode and $\mathrm{Ag} / \mathrm{AgCl}$ pseudo reference electrode, in a solution of tetrabutylammonium perchlorate in acetonitrile, under argon. Measurements were calibrated using the ferrocene/ferrocenium redox couple as the internal standard. Where available, the oxidation and reduction potentials of the thin films were used, according to the method reported by Thelakkat et al., ${ }^{50}$ to estimate the HOMO and LUMO levels. Copolymers containing oxadiazole subunits (P2 and P6) and triazole subunits (P3 and P7) gave no observable reduction or oxidation responses. The copolymers containing carbazole and triarylamine repeat units gave irreversible oxidation responses. Some of the copolymers dissolved from the surface of the working electrode, during electrochemical measurements. As a result, the oxidations for copolymers P1, P4 and P8 were nonreproducible; for copolymer $\mathbf{P 8}$, the oxidation at $0.62 \mathrm{~V}$ becomes weaker with successive cycles. For copolymer $\mathbf{P 4}$ the peak at $0.62 \mathrm{~V}$ decreases, while the shoulder at $0.50 \mathrm{~V}$ 
Keyworth et al., 'The tuning of the energy levels of dibenzosilole copolymers....'

increases; for copolymer P1 the peak at $0.90 \mathrm{~V}$ decreases while the shoulder at $0.70 \mathrm{~V}$ increases (Figures S1-S5). The cyclic voltammetry measurements are therefore somewhat ambiguous, which may explain the discrepancies with some of the photoelectron spectroscopy in air (PESA) measurements (see later).

Table 3 Cyclic voltammetry data obtained from reduction and oxidation sweeps performed on spin-cast thin films.

\begin{tabular}{lcccccc}
\hline Copolymer & Dibenzosilole & Co-monomer & $\begin{array}{c}\text { Oxidation } \\
\text { Potential } \\
(\mathrm{V})\end{array}$ & $\begin{array}{c}\text { HOMO } \\
\text { Energy } \\
(\mathrm{eV})\end{array}$ & $\begin{array}{c}\text { Reduction } \\
\text { Potential } \\
(\mathrm{V})\end{array}$ & $\begin{array}{c}\text { LUMO } \\
\text { Energy } \\
(\mathrm{eV})\end{array}$ \\
\hline $\mathbf{P 1}+$ & $\mathbf{1}$ & 3,6 -Carbazole & 0.72 & -5.52 & $*$ & $*$ \\
$\mathbf{P 2}$ & $\mathbf{1}$ & Oxadiazole $(\mathbf{9})$ & $*$ & $*$ & $*$ & $*$ \\
$\mathbf{P 3}$ & $\mathbf{1}$ & Triazole $(\mathbf{1 1})$ & $*$ & $*$ & $*$ & $*$ \\
$\mathbf{P 4}+$ & $\mathbf{1}$ & $\mathrm{Ar}_{3} \mathrm{~N}(\mathbf{7})$ & 0.53 & -5.33 & $*$ & $*$ \\
$\mathbf{P 5}$ & $\mathbf{2}$ & $3,6-$ Carbazole & 0.68 & -5.48 & $*$ & $*$ \\
$\mathbf{P 6}$ & $\mathbf{2}$ & Oxadiazole $(\mathbf{9})$ & $*$ & $*$ & $*$ & $*$ \\
$\mathbf{P 7}$ & $\mathbf{2}$ & $\operatorname{Triazole}_{(11)}$ & $*$ & $*$ & $*$ & $*$ \\
$\mathbf{P 8} \dagger$ & $\mathbf{2}$ & $\operatorname{Ar}_{3} \mathrm{~N}(\mathbf{7})$ & 0.56 & -5.36 & $*$ & $*$
\end{tabular}

Note: Glass-carbon working electrode. $\mathrm{Ag} / \mathrm{AgCl}$ pseudo reference electrode, platinum wire counter electrode, $0.1 \mathrm{M}$ tetrabutylammonium perchlorate in acetonitrile, under a blanket of argon. Oxidation sweeps performed at $1000 \mathrm{mV} / \mathrm{s}$ and used to calculate HOMO energy; reduction sweeps performed at $100 \mathrm{mV} / \mathrm{s}$ for LUMO energy measurement; $\dagger=$ non reproducible, $\ddagger=$ non reproducible, new peak appearing; $*=$ not observed

The optical energy gaps were calculated from the extrapolated absorption onset wavelengths of the UV-Vis spectra (vide supra). Alongside these measurements, the ionisation potential (used as an estimate for HOMO energy) of each of the copolymers was recorded using Photoelectron Emission Spectroscopy in Air (PESA). Samples were spincoated onto glass slides and a Riken-Keiki Co. ACII spectrometer was used to measure the ionisation potentials, according to the method described by Winzenberg et al. ${ }^{51}$ The orbital energies and $\mathrm{E}_{\mathrm{g}}$ obtained using the two methods were similar for all samples, where redox responses were observed. The best correlations were found for the copolymers containing 2,7-dibenzosilole repeat units. 
Keyworth et al., 'The tuning of the energy levels of dibenzosilole copolymers....'

On examination of the derived HOMO-LUMO energy levels, certain trends emerge. Within the group of copolymers containing 3,6-linked dibenzosilole, those materials which include a hole-transporting subunit (P4 - triarylamine, P1 - carbazole) have a hole-blocking nature, due to low HOMO levels $(\mathbf{P 4}$ : $-5.62 \mathrm{eV}$; P1: $-5.77 \mathrm{eV})$. Those which include an electron-transporting subunit (P2 - oxadiazole, P3 - triazole) have an electron-blocking nature, due to high LUMO levels $(\mathbf{P} 2:-1.72 \mathrm{eV}$; P3: $-1.76 \mathrm{eV})$. It can be seen, therefore, that for 3,6-dibenzosilole copolymers, the transport properties of the material are opposite to the transporting nature of the co-monomer subunit.

This trend is reversed, however, for the copolymer materials containing 2,7-dibenzosilole subunits. For the copolymers containing a hole-transporting subunit (P8 - triarylamine, P5 carbazole), a hole-transporting nature is observed, due to raised HOMO levels (P8: $-5.43 \mathrm{eV}$; P5: $-5.47 \mathrm{eV})$. For those materials containing an electron-transporting subunit (P6 oxadiazole, P7 - triazole), an electron-transporting nature is observed, due to lowered LUMO levels (P6: -2.42 eV; P7: -2.53 eV).

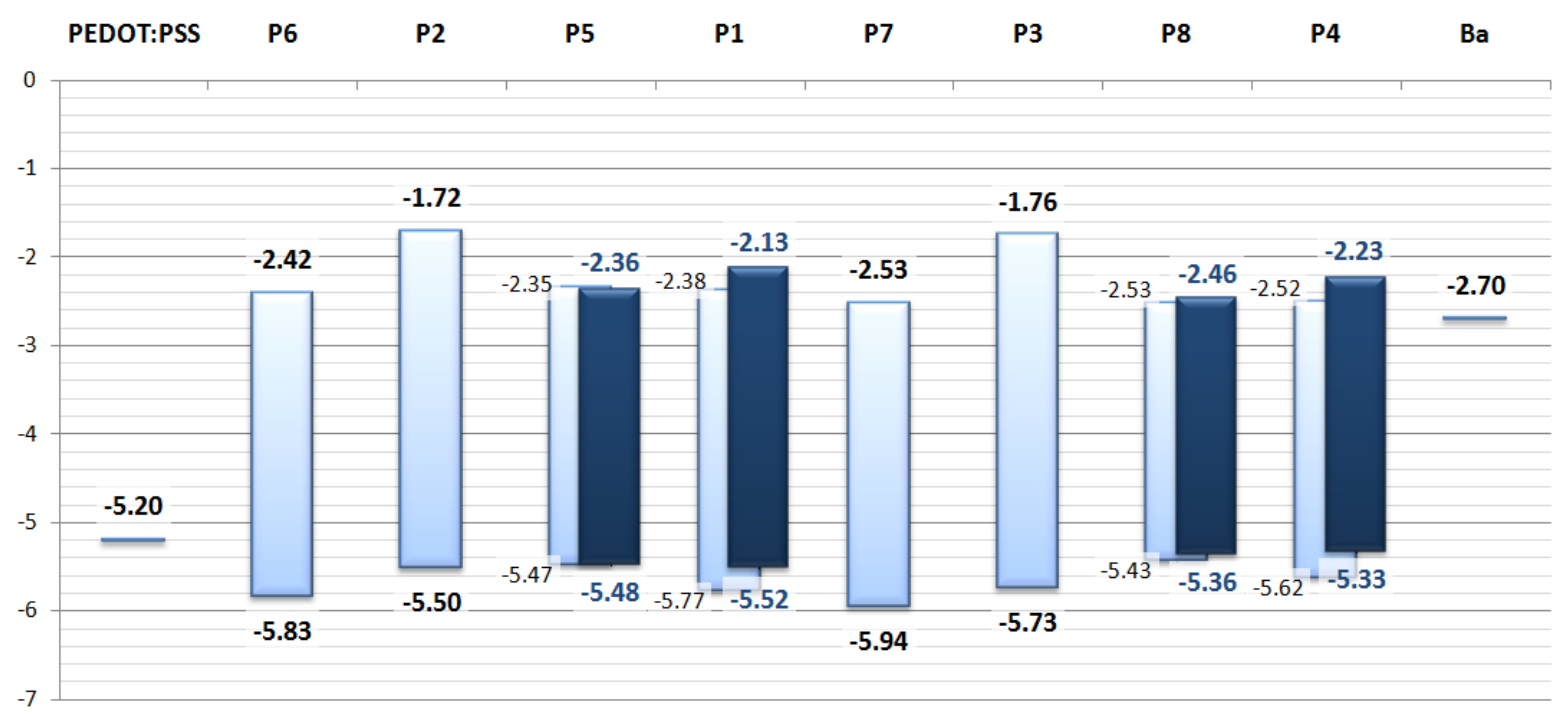

Figure 6 Comparison of copolymer energy levels, as determined CV measurements and PESA measurements. [Note: $\mathrm{E}_{\mathrm{g}}$ determined optically by UV-Vis absorption onset. Dark blue bars are values obtained from CV; light blue from PESA. No CV data for white bars; values from PESA and UV-Vis only] 
Keyworth et al., 'The tuning of the energy levels of dibenzosilole copolymers....'

The copolymers with triarylamine and carbazole repeat units have higher HOMO energies and thus would be expected to show better hole-transport, whilst the copolymer with oxadiazole and triazole could show electron-transport, due to their lowered LUMO energies. Another factor to note is that the 2,7-dibenzosilole copolymers show lower $\mathrm{E}_{\mathrm{g}}$ compared with the 3,6-linked counterparts. For a single layer PLED device, with conventional configuration ITO/PEDOT:PSS/ anode and LiF/Al or $\mathrm{Ba} / \mathrm{Al}$ cathode structures, copolymer $\mathbf{P 8}$ would be expected to have the greatest efficiency due to having the lowest barriers for charge injection at both the anode and cathode.

\section{Light Emitting Diodes (PLEDs)}


Keyworth et al., 'The tuning of the energy levels of dibenzosilole copolymers....'

For each of the different emissive materials, a set of four PLED devices, each with 8 pixels, was prepared with the configuration: Glass / ITO / PEDOT:PSS (10nm) / copolymer P1-P8 $(50 \mathrm{~nm}) / \mathrm{Ba}(0.5 \mathrm{~nm}) / \mathrm{Al}(100 \mathrm{~nm})$. In general, there were difficulties processing and encapsulating the copolymers and the films showed a range of defects (pin-hole, comet type) and significant de-lamination of the active layer. The electroluminescence spectra of copolymers P4, P5 and P8 at a driving voltage of 9V are shown in Figure 7. The spectrum for P5 (containing 2,7-dibenzosilole-carbazole repeat units) showed electroluminescence in the blue region, which was slightly red-shifted $(\sim 10 \mathrm{~nm})$ compared with the photoluminescence spectrum (Figure 4). P8 (2,7-dibenzosilole-triarylamine) showed very low intensity electroluminescence in both the blue and red regions of the spectrum, with the blue emission being dominant.

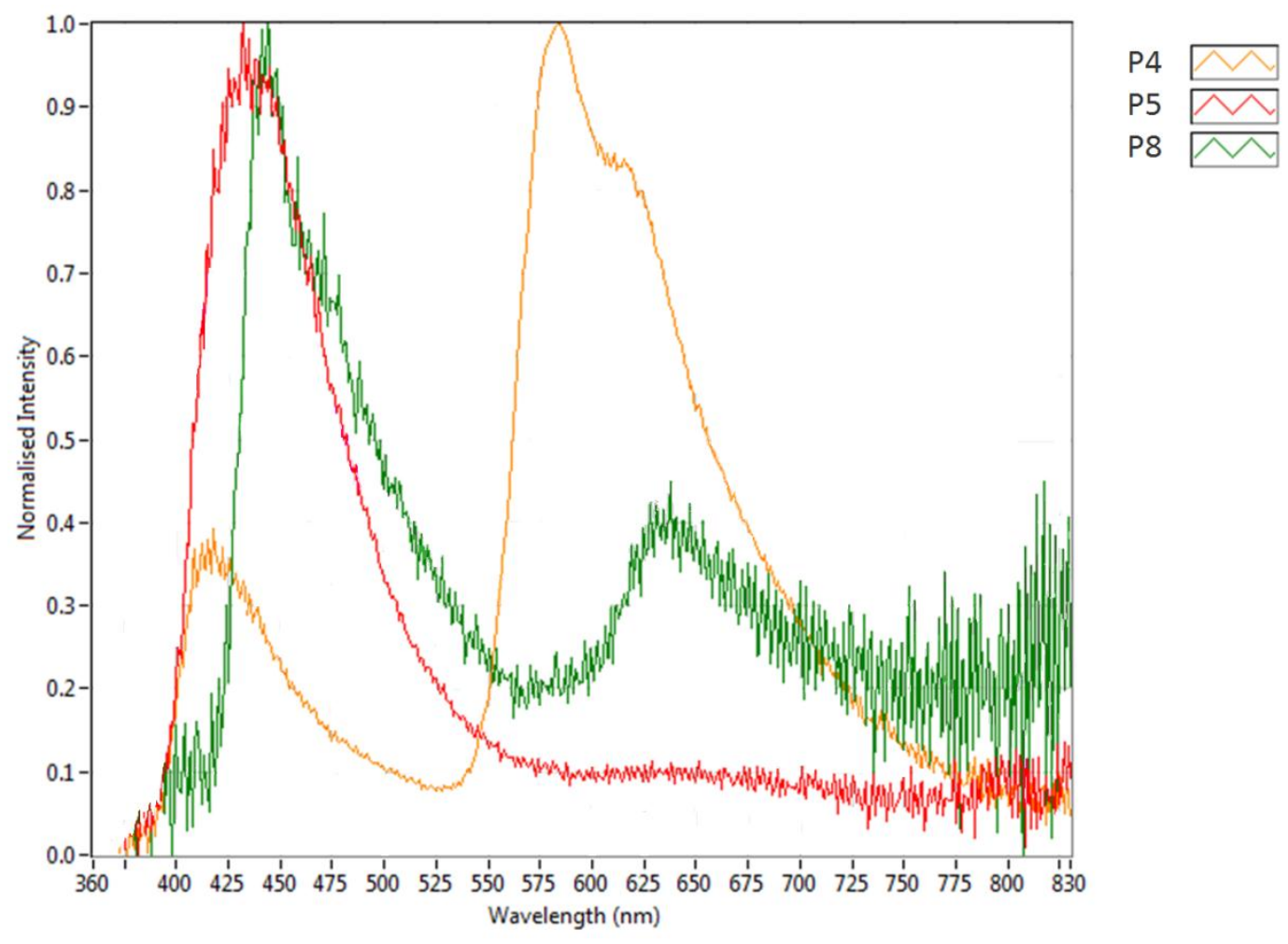

Figure 7 Electroluminescence spectra of copolymers P4, P5 and P8, recorded at 9 V and normalised. 
Keyworth et al., 'The tuning of the energy levels of dibenzosilole copolymers....'

P4 (3,6-dibenzosilole-triarylamine) showed higher intensity EL, but surprisingly the emission is mainly in the red region of the spectrum, with only a minor blue emission. Table 4 summarises the CIE coordinates and external quantum efficiencies (EQE), while comparing the values with the PL CIE coordinates. Only P5 shows a reasonable agreement between optical and electronic spectra. The other copolymers all showed some red-emission. This was probably due to problems controlling the thickness of emissive layer (in practice, this was potentially far greater than $50 \mathrm{~nm}$ ) and to the difficulties in obtaining uniform, smooth films with these copolymers. Changes in the emissive layer thickness have been shown to lead to significant changes in device efficiencies and emission colour for polyfluorenes. ${ }^{52}$ These changes can be caused by an optical interference effect within the "weak microcavity, ${ }^{53}$ Changes in film morphology at the point of light emission, along with selfabsorption by the emissive material can also have a great effect on the device output. Simulations of emission from a white OLED device have shown that as the zone of emission can affect the out-coupling of different wavelengths of light; with larger distances between cathode and emission zone favouring red light out-coupling. ${ }^{54}$

Table 4 Summary of the emission properties of the copolymers.

\begin{tabular}{cccc}
\hline Copolymer & PL CIE coordinates & Device CIE coordinates & QE Factor \\
\hline P4 & {$[0.16,0.05]$} & {$[0.48,0.35]$} & 0.006 \\
P5 & {$[0.16,0.07]$} & {$[0.20,0.15]$} & 0.011 \\
P8 & {$[0.15,0.10]$} & {$[0.26,0.23]$} & 0.010
\end{tabular}

$\mathrm{QE}=$ quantum efficiency, as determined by division of current passing through device by number of photons detected (at the electroluminescence maximum wavelength)

\section{Field Effect Transistors (FETs)}

In order to determine the charge transport characteristics of the copolymers, organic fieldeffect transistors (OFETs) were fabricated and tested (Table 5). Only the copolymers with 
Keyworth et al., 'The tuning of the energy levels of dibenzosilole copolymers....'

smallest $\mathrm{E}_{\mathrm{g}}$ and HOMO levels closest to the work-function of gold $(\sim 5.1 \mathrm{eV})$ : P4, P5 and P8, were selected for investigation.

A bottom-contact, bottom-gate (BCBG) device architecture was employed (inset in Figure 8(a)) and the OFETs were fabricated on a highly-doped silicon substrate, which acted as a common gate electrode. A thermally grown $200 \mathrm{~nm}$ layer of silicon dioxide was then used as the gate dielectric. The $\mathrm{SiO}_{2}$ layer was treated with hexamethyldisilazane (HMDS) in order to improve crystallisation. ${ }^{55}$ Gold source and drain electrodes were patterned using standard photolithography.

Table 5 OFET device mobilities and on/off ratios.

\begin{tabular}{cccc}
\hline Copolymer & $\begin{array}{c}\text { Linear Mobility } \\
\mu\left(\mathrm{cm}^{2} \mathrm{~V}^{-1} \mathrm{~s}^{-1}\right)\end{array}$ & $\begin{array}{c}\text { Saturation Mobility } \\
\mu\left(\mathrm{cm}^{2} \mathrm{~V}^{-1} \mathrm{~s}^{-1}\right)\end{array}$ & $\begin{array}{c}\text { Current } \\
\text { On/Off Ratio }\end{array}$ \\
\hline P4 & $1.1 \times 10^{-5}$ & $2.7 \times 10^{-5}$ & $1.0 \times 10^{3}$ \\
P5 & $3.0 \times 10^{-6}$ & $1.1 \times 10^{-5}$ & $1.0 \times 10^{3}$ \\
P8 & $1.5 \times 10^{-4}$ & $2.7 \times 10^{-4}$ & $1.0 \times 10^{5}$ \\
\hline
\end{tabular}

Of the copolymers studied for use in OFETs, $\mathbf{P 8}$ showed the best performance, while $\mathbf{P 4}$ and P5 gave lower mobilities and current on/off ratios (Table 5). The device characteristics for OFET devices fabricated using P8 show negligible hysteresis and a large current on/off ratio. Optimum results were achieved when using an annealing temperature of $100{ }^{\circ} \mathrm{C}$. The transfer characteristics (drain current $I_{D}$ as a function of gate voltage $V_{G}$ ) are shown in Figure 8(a), while the output characteristics (drain current $I_{D}$ as a function of drain voltage $V_{D}$ ) are shown in Figure 8(b). Using standard semiconductor models, ${ }^{56}$ the field effect mobility was determined, from the transfer characteristics, to be approximately $3 \times 10^{-4} \mathrm{~cm}^{2} \mathrm{~V}^{-1} \mathrm{~s}^{-1}$. From plots of $I_{D}^{1 / 2}$ against $V_{G}$ (data not shown) the threshold voltage was determined to be $-31 \mathrm{~V}$. The current on-off ratio was estimated to be $10^{5}$. 
Keyworth et al., 'The tuning of the energy levels of dibenzosilole copolymers....'
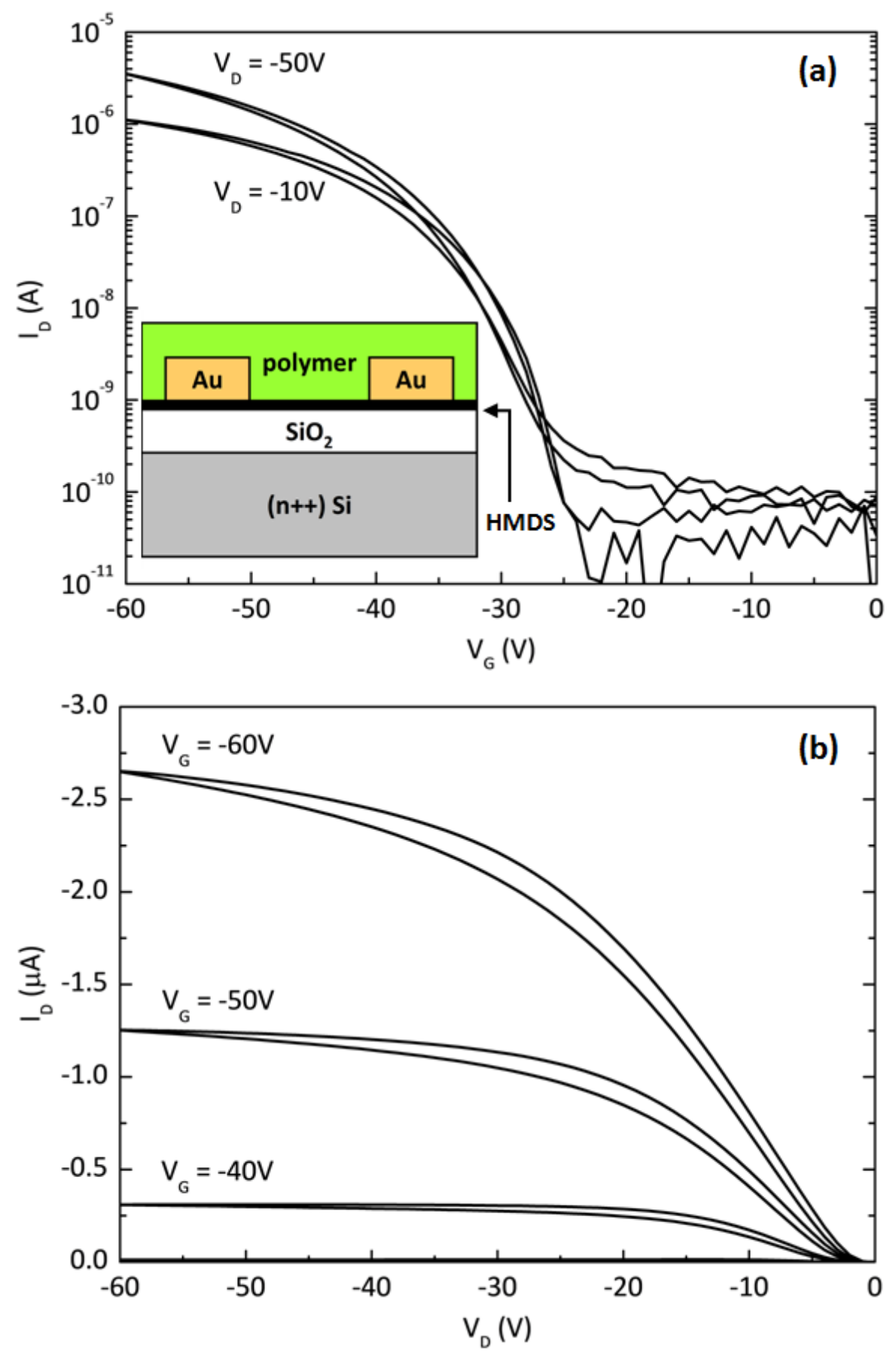

Figure 8 (a) Transfer characteristics (schematic cross-section inset); (b) output characteristics of P8-based bottom-contact, bottom-gate organic field-effect transistor $(\mathrm{L}=10 \mu \mathrm{m}$ and $\mathrm{W}=20 \mathrm{~mm})$ measured after annealing at $100^{\circ} \mathrm{C}$ for 1 hour under ambient pressure $\mathrm{N}_{2}$.

\section{Conclusions}


Keyworth et al., 'The tuning of the energy levels of dibenzosilole copolymers....'

A series of eight novel copolymers have been synthesised by Suzuki polycondensation. A significant improvement in the overall yield for the synthesis of 9,9-dioctyl-2,7-dibenzosilole (2) has been achieved and the synthesis of three novel co-monomers is reported.

The copolymers were fully characterised using a range of spectroscopic and optoelectronic techniques. The UV-Vis spectra were used, in conjunction with cyclic voltammetry and PESA, to derive the frontier orbital energies. A clear pattern was observed in the hypsochromic shift in absorption from 2,7-linked to 3,6-linked dibenzosilole copolymers. As a result, materials containing the 2,7-linked dibenzosilole repeat units had a significantly smaller energy gap than that of the 3,6-linked counterparts. The relative charge transport properties of the copolymers were altered in a predictable manner by the inclusion of either hole- or electron-transporting subunits, and were dependent on the linkage positions within the dibenzosilole sub-unit.

From the photoluminescence measurements and frontier orbital energy levels, all of the copolymer materials showed promise for use as blue OLED emissive materials (often meeting the CIE coordinate specifications for blue emission), with the exception of the UVemitters P2 and P3. However, the electroluminescence performance of the PLED devices was poor. This is primarily ascribed to the film-forming capabilities of the copolymers. Devices fabricated with copolymers $\mathbf{P 4}$ and $\mathbf{P 8}$ gave the highest luminance levels and current densities (within the voltage range 8 to $12 \mathrm{~V}$ ). These materials both feature a triarylamine subunit and exhibit the lowest LUMO levels within the series of copolymers. This suggests that the reduced electron-injection barrier led to improved device performance, which in turn implies that the electron-injection barrier is of more importance than the barrier for holeinjection, for the dibenzosiloles tested and the device architecture employed. The device containing copolymer P4 displayed mostly red emission, while that containing $\mathbf{P 8}$ displayed mostly blue emission. It can therefore be envisaged that the higher HOMO level of P8 (-5.43 
Keyworth et al., 'The tuning of the energy levels of dibenzosilole copolymers....'

$\mathrm{eV}$ ) reduces the hole-injection barrier, leading to improved charge injection balance and increased polaron recombination within the desired zone of emission. In the case of $\mathbf{P 4}$, a lowered HOMO level $(-5.62 \mathrm{eV})$ increased the hole-injection barrier, which leads to an unbalanced charge injection and the recombination of polarons closer to the PEDOT:PSS/emissive layer interface than within the desired emission zone.

Carbazole-containing copolymers P1 and P5 afforded devices with lower luminance levels and current densities than those containing P4/P8. Both of these materials feature slightly higher LUMO levels than the triarylamine-containing copolymers (P1: $-2.38 \mathrm{eV}$; P5: -2.35 eV). Accordingly, the electron-injection barrier is increased, leading to the observed decrease in device performance. The device containing copolymer P5 produced the best observable emission profile (Figure 7), showing a pure blue output, while the device containing P1 produced the lowest intensity and widest emission profile, giving a mixture of blue and red electroluminescence. The higher HOMO level of P5 $(-5.47 \mathrm{eV})$ reduces the hole-injection barrier, thereby improving charge injection balance and resulting in polaron recombination / emission occurring within the desired emission zone. In the case of P1 however, the lower HOMO level $(-5.77 \mathrm{eV})$ leads to an increased hole-injection barrier and a poor balance of charge injection, hence radiation recombination of polarons will occur predominantly towards the PEDOT:PSS/emissive layer interface

In contrast with these materials, copolymers containing electron-transporting oxadiazole (P2 and P6) and triazole (P3 and P7) subunits afforded the worst devices, with only the device containing copolymer $\mathbf{P 6}$ giving any measurable output. These materials had the highest LUMO (P2 and P3) or lowest LUMO (P6 and P7) levels and therefore the greatest barriers to electron- and hole-injection respectively. From within this grouping, copolymer P6 had the most balanced charge injection barriers and the smallest energy gap, due to the 
Keyworth et al., 'The tuning of the energy levels of dibenzosilole copolymers....'

2,7-dibenzosilole subunit, which may explain why it was the only material to give a working device.

In light of the promising photoluminescence measurements but modest electroluminescence performances of the dibenzosilole copolymers, further optimisation of polymerisation conditions in order to maximise molecular weight and improve film-forming abilities would be worthwhile and could significantly improve device performances.

Finally, an OFET prepared using $\mathbf{P 8}$ showed good hole mobility and a high current on/off ratio. This promising preliminary result implies that other copolymers incorporating dibenzosilole and hole-transporting subunits could be used in order to raise the peak charge mobility.

\section{Acknowledgements}

The authors would like to thank Imperial College London for provision of a student bursary and a doctoral training award, Cambridge Display Technology Ltd. for financial support via a CASE award, Ann Wilson for assistance with material characterisation, and CSIRO for access to their AC-II spectrometer.

\section{Experimental Section}

\section{General methods}

Proton NMR spectra were performed on a Bruker Av-400 (400 MHz), carbon-13 NMR spectra were recorded with proton decoupling on a Bruker Av-400 (100 MHz). Silicon-29 NMR spectra were performed on a Bruker Av-400 (79 MHz). Chemical shifts are reported in ppm relative to residual protons in the commercially available deuterated solvents. All spectra were analysed using MestreNova software, from MestreLab. GPC data was collected using a Polylabs PCL-50, with 2 MIXED-D columns in series at $25^{\circ} \mathrm{C}$, using THF as the 
Keyworth et al., 'The tuning of the energy levels of dibenzosilole copolymers....'

eluent and narrow molecular weight polystyrene standards as calibrants. Flash column chromatography was performed on Merck Kieselgel 60 (230-400 mesh) silica. Analytical thin layer chromatography (TLC) was performed on pre-coated $0.25 \mathrm{~mm}$ thick Merck 5715 Kieselgel 60 F254 silica gel plates and observed under $254 \mathrm{~nm}$ or $366 \mathrm{~nm}$ ultraviolet light. Melting points were determined with a Gallenkamp melting point apparatus and are uncorrected. Elemental analyses were performed by Mr Steven Boyer, London Metropolitan University. X-ray crystallography structure refinements were performed by Dr. A. J. P. White, Department of Chemistry, Imperial College London. Photoluminescence spectra were recorded using a Varian Cary Eclipse Fluorescence Spectrometer. Thin films were prepared by spin casting toluene solutions of the copolymers $\left(15 \mathrm{mg}\right.$ in $\left.1 \mathrm{~cm}^{3}\right)$ on cut microscope slides. UV/Vis spectra were recorded in solution, using a Perkin Elmer LAMBDA 25 spectrophotometer. Infrared absorptions were measured in the solid state (or neat liquid in the case of oil samples) using a Perkin Elmer 400 FT spectrometer. Photoelectron Spectroscopy in Air (PESA) measurements were made using a Riken Keiki AC-II at Cambridge Display Technology and at CSIRO Materials Science and Engineering. Differential scanning calorimetry measurements were recorded using a Perkin Elmer Pyris 1 DSC instrument with liquid nitrogen as coolant. $10-15 \mathrm{mg}$ of the polymer sample was sealed in an aluminium pan with a crimping tool. The sample was heated from $30{ }^{\circ} \mathrm{C}$ to $200{ }^{\circ} \mathrm{C}$ at a heating rate of $40{ }^{\circ} \mathrm{C} / \mathrm{min}$, held for 1 minute at $200{ }^{\circ} \mathrm{C}$, then cooled to $30{ }^{\circ} \mathrm{C}$ at a rate of 40 ${ }^{\circ} \mathrm{C} / \mathrm{min}$. This cycle was repeated three times, then twice more with a heating rate of 100 ${ }^{\circ} \mathrm{C} / \mathrm{min}$. Thermogravimetric analysis measurements were recorded using a Perkin Elmer Pyris 1 TGA instrument. $5-10 \mathrm{mg}$ of the copolymer sample were loaded into the crucible and accurately weighed. The sample was then heated from $100{ }^{\circ} \mathrm{C}$ to $650{ }^{\circ} \mathrm{C}$, under a $20 \mathrm{~mL} /$ min flow of nitrogen. The decomposition temperature, $\mathrm{T}_{\mathrm{d}}$, was determined by the temperature at which 5\% mass loss of the sample occurred. Low resolution mass 
Keyworth et al., 'The tuning of the energy levels of dibenzosilole copolymers....'

spectrometry was performed on a VG Autospec Q spectrometer (EI) or an LCT Premier electrospray spectrometer (ESI). High resolution mass spectrometry was performed on a VG Autospec Q spectrometer.

\section{Device Fabrication}

PLED device fabrication was conducted using an MBraun nitrogen-filled glove box, within a clean-room environment at Cambridge Display Technology Ltd. Pre-patterned ITO-covered glass plates ( $45 \times 45 \times 0.7 \mathrm{~mm})$ were annealed and UV / ozone cured for 2 min before a 10 nm layer of PEDOT:PSS was deposited by spin-coating (Dispense phase - $300 \mathrm{rpm}$ (acceleration $100 \mathrm{rpm}^{2}$ ) $4 \mathrm{~s}$; spin phase - lid closed, $2610 \mathrm{rpm}\left(\right.$ acceleration $5000 \mathrm{rpm}^{2}$ ) $7 \mathrm{~s}$; Dry phase - lid open, $400 \mathrm{rpm}$ (acceleration $100 \mathrm{rpm}^{2}$ ) $60 \mathrm{~s}$ ). The plates were then annealed at $170{ }^{\circ} \mathrm{C}$ for 15 minutes and a $50 \mathrm{~nm}$ layer of the emissive layer (from the range of copolymers) was spin-coated and dried before briefly annealing at $80{ }^{\circ} \mathrm{C}$. A metal evaporation system, with a shadow-mask grille, was used to deposit a $0.5 \mathrm{~nm}$ layer of elemental barium, followed by $100 \mathrm{~nm}$ of elemental aluminium. The whole device was then encapsulated within a moisture / oxygen impermeable casing, complete with electrical pin contacts attached to the separated electrodes. A purpose-built testing rig was used to automatically analyse the photophysical properties and current/voltage characteristics of each batch of devices. Spin trials were performed by spinning polymer solutions onto plain 0.7 mm x $45 \mathrm{~mm}$ x $45 \mathrm{~mm}$ glass plates within a glovebox. The sample plates were subsequently removed from the glovebox, scored with a needle and the surface profile measured using a Dectak stylus profiler. The spin trials and device spin-coating for polymer $\mathbf{P 3}$ were performed on an open-bowl spinner with a vacuum chuck.

OFETs were fabricated on a proprietary silicon substrate from Philips. After photolithographic patterning of the gold electrodes, a $10 \mathrm{mg} / \mathrm{mL}$ solution (chlorobenzene) of 
Keyworth et al., 'The tuning of the energy levels of dibenzosilole copolymers....'

copolymer was spin-cast onto the substrate, under a nitrogen atmosphere. The sample was annealed for one hour, at $100{ }^{\circ} \mathrm{C}$. Electrical characterisation was carried out using a Keithley 4200 semiconductor parameter analyser, under a nitrogen atmosphere.

\section{Materials}

Unless otherwise stated, all reactions were conducted under dry nitrogen, with a nitrogenfilled dual manifold using standard Schlenk techniques. All solvents and reagents were obtained from commercial sources and used as received unless otherwise stated. $N, N$,Dimethylformamide was stirred over calcium hydride $(20 \mathrm{~h})$, distilled in vacuo and stored under nitrogen. Tetrahydrofuran, diethyl ether, toluene, and hexane and were distilled from sodium and stored under nitrogen. Methylene chloride was refluxed over calcium hydride, distilled and stored under nitrogen. 2,2'-Dibromobiphenyl, ${ }^{57}$ and N-octyl-9H-carbazole, ${ }^{45}$ were prepared according to literature procedures. For the synthesis of 2,2'-diiodobiphenyl, 5,5'-dibromo-2,2'-diiodobiphenyl, 3,6-dibromo-N-octyl-9H-carbazole, 3,6-dibromo-9,9dioctyl-9H-dibenzosilole, 9,9-dioctyl-3,6-bis(4,4,5,5-tetramethyl-1,3,2-dioxaborolan-2-yl)9H-dibenzosilole (1), 2,7-bis(4,4,5,5-tetramethyl-1,3,2-dioxaborolane-2-yl)-9,9dioctyldibenzosilole (2), 4,4'-dibromo-2,2'-dinitrobiphenyl (3), 4,4'-dibromobiphenyl-2,2'diamine (4), 2,7-dibromo-9,9-di-n-octyldibenzosilole (6) and a scheme for the synthetic route to dibenzosilole monomer 1, please refer to the ESI. Polymer P8 was further purified for OFET fabrication by use of a palladium scavenging agent (see ESI for procedure).

\section{Synthesis}

4,4'-Dibromo-2,2'-diiodobiphenyl (5). ${ }^{24}$ A 3-necked flask equipped with a low temperature thermometer was charged with 4,4'-dibromobiphenyl-2,2'-diamine (1.00 g, 2.6 mmol), aqueous $\mathrm{HCl}(10 \mathrm{~mL}, 32 \% \mathrm{w} / \mathrm{w}), \mathrm{H}_{2} \mathrm{O}(40 \mathrm{~mL})$ and acetonitrile $(40 \mathrm{~mL})$. The 
Keyworth et al., 'The tuning of the energy levels of dibenzosilole copolymers....'

mixture was warmed and stirred until the diamine was dissolved, then cooled to $-10{ }^{\circ} \mathrm{C}$, giving a light yellow precipitate. A solution of sodium nitrite $(0.92 \mathrm{~g}, 13.4 \mathrm{mmol})$ in $\mathrm{H}_{2} \mathrm{O}(5$ $\mathrm{mL}$ ) was cooled to $0{ }^{\circ} \mathrm{C}$ and added slowly to the reaction mixture, keeping the reaction temperature between -10 and $-5{ }^{\circ} \mathrm{C}$. The reaction was stirred at this temperature for one hour. A solution of $\mathrm{KI}(4.44 \mathrm{~g}, 26.7 \mathrm{mmol})$ in $\mathrm{H}_{2} \mathrm{O}(10 \mathrm{~mL})$ was cooled to $0{ }^{\circ} \mathrm{C}$ and added dropwise via cannula to the reaction mixture with vigorous stirring, whilst maintaining the reaction temperature between $-15{ }^{\circ} \mathrm{C}$ and $-10{ }^{\circ} \mathrm{C}$. Once addition was complete, the reaction was warmed to room temperature and then heated to $80{ }^{\circ} \mathrm{C}$ for $20 \mathrm{~h}$. The product was extracted with chloroform ( $3 \times 100 \mathrm{~mL}$ ) and the combined organic phases washed with aq. $\mathrm{Na}_{2} \mathrm{~S}_{2} \mathrm{O}_{3}$ $(200 \mathrm{~mL}), \mathrm{H}_{2} \mathrm{O}(200 \mathrm{~mL})$ and brine $(200 \mathrm{~mL})$, dried $\left(\mathrm{MgSO}_{4}\right)$ and evaporated to dryness. Purification by column chromatography on silica gel, using hexane as eluent, followed by recrystallisation from hexane yielded the title compound $(0.88 \mathrm{~g}, 1.56 \mathrm{mmol}, 58 \%)$ as colourless needles; mp 89-90 ${ }^{\circ} \mathrm{C}$ (from hexane, lit. mp $89{ }^{\circ} \mathrm{C}$ ) ${ }^{24} ; R_{\mathrm{F}}$ (hexane) $0.32 ; \delta_{\mathrm{H}}(400$ $\left.\mathrm{MHz}, \mathrm{CDCl}_{3}\right) 7.03(2 \mathrm{H}, \mathrm{d}, J$ 8.1, $\mathrm{ArH}), 7.56(2 \mathrm{H}, \mathrm{dd}, J 8.11 .9, \operatorname{Ar} H), 8.09(2 \mathrm{H}, \mathrm{d}, J 1.9$, $\mathrm{Ar} H)$. The $\delta_{\mathrm{H}}$ data is in agreement with literature values. ${ }^{24}$

$N, N$-bis(4-bromobenzene)-4-sec-butylaniline (7). An oven-dried multi-necked roundbottomed flask was evacuated and filled with nitrogen. 4-sec-Butylaniline (2.46 mL, 16.1 mmol), 1-bromo-4-iodobenzene (10.00 g, $35.4 \mathrm{mmol})$, 1,10-phenanthroline monohydrate (127 mg, $0.6 \mathrm{mmol})$ and toluene $(55 \mathrm{~mL})$ were added under nitrogen. A Dean-Stark trap was fitted and the reaction mixture was stirred and degassed with nitrogen for 20 minutes. Copper (I) chloride $(64 \mathrm{mg}, 0.6 \mathrm{mmol})$ and ground, oven-dried potassium hydroxide $(7.21 \mathrm{~g}, 128.5$ mmol), were added under nitrogen and the mixture was stirred and degassed for a further 10 minutes, before being stirred for $20 \mathrm{~h}$ at reflux, under a nitrogen atmosphere. The reaction was allowed to cool to room temperature and distilled water $(50 \mathrm{~mL})$ was added. The aqueous layer was extracted with toluene $(3 \times 50 \mathrm{~mL})$ and the combined organic layers were 
Keyworth et al., 'The tuning of the energy levels of dibenzosilole copolymers....'

washed with $10 \%$ aqueous ammonia solution $(100 \mathrm{~mL})$, distilled water $(100 \mathrm{~mL}), 10 \%$ aqueous thiosulphate solution $(100 \mathrm{~mL})$ and brine $(100 \mathrm{~mL})$. The solution was dried $\left(\mathrm{MgSO}_{4}\right)$ and the solvent was removed under vacuum to give a dark orange oil. Purification by column chromatography on silica, using petroleum ether $40-60 \%$ with $2 \%$ triethylamine, followed by recrystallisation from isopropyl alcohol afforded the title compound (2.41 g, $5.2 \mathrm{mmol}, 33 \%)$ as white needles; mp $108-109{ }^{\circ} \mathrm{C}$ (from isopropyl alcohol); (Found: $\mathrm{C}, 57.5 ; \mathrm{H}, 4.6 ; \mathrm{N}, 2.9$. $\mathrm{C}_{22} \mathrm{H}_{21} \mathrm{Br}_{2} \mathrm{~N}$ requires: C, 57.5; H, 4.6; N, 3.05\%); $R_{\mathrm{F}}\left(\right.$ Petrol-2\% $\left.\mathrm{Et}_{3} \mathrm{~N}\right) 0.52 ; \delta_{\mathrm{H}}(400 \mathrm{MHz}$, $\left.\mathrm{CDCl}_{3}\right) 0.83\left(3 \mathrm{H}, \mathrm{t}, J 7.5, \mathrm{CH}_{3}\right), 1.21\left(3 \mathrm{H}, \mathrm{d}, J 7.0, \mathrm{CH}_{3}\right), 1.53-1.63\left(2 \mathrm{H}, \mathrm{m}, \mathrm{CH}_{2}\right), 2.59(1 \mathrm{H}$, tq, J 7.0, 7.0, $\operatorname{Ar} H), 6.92(4 \mathrm{H}, \mathrm{d}, J 9.0, \operatorname{Ar} H), 6.98(2 \mathrm{H}, \mathrm{d}, J 8.5, \operatorname{Ar} H), 7.11(2 \mathrm{H}, \mathrm{d}, J 8.5$, $\operatorname{ArH}), 7.33(4 \mathrm{H}, \mathrm{d}, J$ 9.0, $\mathrm{ArH}) ; \delta_{\mathrm{C}}\left(100 \mathrm{MHz}, \mathrm{CDCl}_{3}\right)$ 12.6, 22.1, 31.7, 41.7, 115.3, 125.5, 125.6, 128.7, 132.7, 144.4, 145.0, 147.4; $m / z$ (ES) $458.0120\left([\mathrm{M}+\mathrm{H}]^{+} . \mathrm{C}_{22} \mathrm{H}_{22}{ }^{79} \mathrm{Br}_{2} \mathrm{~N}_{2}\right.$ requires 458.0119), (ES+) 460 (100\%), 245 (19), 153 (21).

$\mathbf{N}, \mathbf{N}^{\prime}$-bis(3-bromobenzoyl)hydrazine (8). A multi-necked round-bottomed flask was charged with 3-bromobenzoyl chloride $(6.00 \mathrm{~mL}, 45.5 \mathrm{mmol})$ and $N$-methyl-2-pyrrolidinone $(200 \mathrm{~mL})$. The mixture was stirred and degassed with nitrogen for 20 minutes and then cooled to $0{ }^{\circ} \mathrm{C}$ before hydrazine monohydrate $(4.42 \mathrm{~mL}, 91.1 \mathrm{mmol})$ was added dropwise under nitrogen. The reaction was stirred overnight at room temperature under a nitrogen atmosphere, then precipitated into distilled water $(1.5 \mathrm{~L})$. The precipitate was collected and washed thoroughly with EtOAc $(500 \mathrm{~mL})$ and petroleum ether $40-60{ }^{\circ} \mathrm{C}(50 \mathrm{~mL})$, then dried under vacuum to afford the title compound $(7.03 \mathrm{~g}, 17.8 \mathrm{mmol}, 78 \%)$ as a fine white powder; $\mathrm{mp}>220{ }^{\circ} \mathrm{C} ; \delta_{\mathrm{H}}(400 \mathrm{MHz}, \mathrm{DMSO}) 7.51(2 \mathrm{H}, \mathrm{dd}, J$ 8.0, 8.0, $\mathrm{ArH}), 7.82(2 \mathrm{H}, \mathrm{d}, J 8.0 \mathrm{Ar} H)$, $7.92(2 \mathrm{H}, \mathrm{d}, J$ 8.0, $\mathrm{ArH}), 8.09$ (2H, s, $\operatorname{Ar} H), 10.67(2 \mathrm{H}, \mathrm{s}, \mathrm{NH})$.

2,5-Bis(3-bromophenyl)-1,3,4-oxadiazole (9). A multi-necked round-bottomed flask was evacuated and filled with nitrogen. $N, N^{\prime}$-bis(3-bromobenzoyl)hydrazine $(1.20 \mathrm{~g}, 3.0 \mathrm{mmol})$ 
Keyworth et al., 'The tuning of the energy levels of dibenzosilole copolymers....'

and phosphorous oxychloride $(40 \mathrm{~mL})$ were added under nitrogen and the mixture was stirred and degassed with nitrogen for 20 minutes. The reaction was then stirred at $130{ }^{\circ} \mathrm{C}$, under nitrogen, for 7 hours. Once cooled to room temperature, the mixture was cautiously added to ice water. The mixture was maintained at $0{ }^{\circ} \mathrm{C}$, whilst $\mathrm{KOH}$ pellets were added, until the solution was $\mathrm{pH}$ neutral. The aqueous layer was extracted with chloroform ( 3 x $50 \mathrm{~mL})$. The combined organic layers were washed with brine $(200 \mathrm{~mL})$, dried $\left(\mathrm{MgSO}_{4}\right)$ and dried in vасио. Recrystallisation from ethanol afforded the title compound (1.01 g, $2.7 \mathrm{mmol}, 88 \%$ ) as fine colourless needles; mp 178-181 ${ }^{\circ} \mathrm{C}$ (from EtOH); (Found: C, 44.2; H, 2.0; N, 7.3. $\mathrm{C}_{14} \mathrm{H}_{8} \mathrm{Br}_{2} \mathrm{~N}_{2} \mathrm{O}$ requires: $\left.\mathrm{C}, 44.2 ; \mathrm{H}, 2.1 ; \mathrm{N}, 7.4 \%\right) ; \delta_{\mathrm{H}}\left(400 \mathrm{MHz}, \mathrm{CDCl}_{3}\right) 7.41(2 \mathrm{H}, \mathrm{dd}, J$ 8.0, 8.0, $\operatorname{Ar} H), 7.69(2 \mathrm{H}, \mathrm{d}, J 8.0 \mathrm{ArH}), 8.08(2 \mathrm{H}, \mathrm{d}, J$ 8.0, $\operatorname{Ar} H), 8.27(2 \mathrm{H}, \mathrm{s}, \operatorname{Ar} H) ; \delta_{\mathrm{C}}(100 \mathrm{MHz}$ $\left.\mathrm{CDCl}_{3}\right)$ 88.8, 89.4, 89.4, 90.5, 90.7, 91.8, 99.0; $\mathrm{m} / z(\mathrm{ES}) 378.9078\left([\mathrm{M}+\mathrm{H}]^{+} . \mathrm{C}_{14} \mathrm{H}_{9}{ }^{79} \mathrm{Br}_{2} \mathrm{~N}_{2} \mathrm{O}\right.$ requires 378.9082), (ES+) $422\left([\mathrm{M}+\mathrm{ACN}+\mathrm{H}]^{+}, 80 \%\right), 381(100), 342(42)$.

1,2-Bis((3-bromophenyl)chloromethylene)hydrazine (10). A multi-necked roundbottomed flask was charged with $N, N^{\prime}$-bis(3-bromobenzoyl)hydrazine $(6.09 \mathrm{~g}, 15.4 \mathrm{mmol})$ and toluene $(120 \mathrm{~mL})$. The mixture was stirred and degassed with nitrogen for 30 minutes, whilst warming to $60{ }^{\circ} \mathrm{C}$. Phosphorous pentachloride (7.05 g, $\left.33.9 \mathrm{mmol}\right)$ was added to reaction under nitrogen and the mixture was stirred at reflux for $20 \mathrm{~h}$. On cooling to room temperature, the resultant yellow precipitate was collected and washed thoroughly with chloroform $(100 \mathrm{~mL})$ to afford the title compound $(1.21 \mathrm{~g}, 2.8 \mathrm{mmol}, 18 \%)$ as yellow crystals; mp 109-110 ${ }^{\circ} \mathrm{C}$; (Found: $\mathrm{C}, 38.6 ; \mathrm{H}, 1.7 . \mathrm{C}_{14} \mathrm{H}_{8} \mathrm{Br}_{2} \mathrm{Cl}_{2} \mathrm{~N}_{2}$ requires $\mathrm{C}, 38.7 ; \mathrm{H}$, $1.9 \%) ; v_{\max } / \mathrm{cm}^{-1}$ (Neat solid) $681,750,790,890,932,1212,1404,1468,1557,1599 ; \delta_{\mathrm{H}}(400$ MHz, DMSO) $7.57(2 \mathrm{H}, \mathrm{dd}, J$ 8.0, $\operatorname{Ar} H), 7.89(2 \mathrm{H}, \mathrm{d}, J$ 8.0, $\operatorname{Ar} H), 8.08(2 \mathrm{H}, \mathrm{d}, J$ 8.0, $\operatorname{Ar} H)$, $8.18(2 \mathrm{H}, \mathrm{s}, \operatorname{Ar} H) ; \delta_{\mathrm{C}}\left(100 \mathrm{MHz}, d_{6}\right.$-DMSO) 122.9 (s), 128.1 (d), 131.0 (d), 132.0 (d), 135.0 (s), 136.1 (s), 159.1 (s); $m / z$ (EI) $431.8426\left(\mathrm{M}^{+} . \mathrm{C}_{14} \mathrm{H}_{8}{ }^{79} \mathrm{Br}_{2}{ }^{35} \mathrm{Cl}_{2} \mathrm{~N}_{2}\right.$ requires 431.8426), 436 
Keyworth et al., 'The tuning of the energy levels of dibenzosilole copolymers....'

(6\%), 434 (7), 432 (3), 399 (7), 218 (12), 183 (100), 119 (13), 102 (32), 93 (16), 75 (19), 49 (23).

3,5-Bis(3-bromophenyl)-4-(4-(octyloxy)phenyl)-1,2,4-triazole (11). A multi-necked round-bottomed flask was charged with 4-octyloxyaniline $(672 \mathrm{mg}, 3.0 \mathrm{mmol})$ and 1,2bis((3-bromophenyl)chloromethylene)hydrazine $(1.20 \mathrm{~g}, 2.8 \mathrm{mmol})$, then evacuated and nitrogen-filled. $N, N$-dimethylaniline $(20 \mathrm{~mL})$ was added under nitrogen and the mixture was stirred and degassed with nitrogen for 20 minutes, then stirred at $135{ }^{\circ} \mathrm{C}$ for 48 hours under a nitrogen atmosphere. The reaction mixture was allowed to cool to room temperature and precipitated into a beaker containing hydrochloric acid $\left(2.0 \mathrm{~mol} \mathrm{dm}^{-3}, 100 \mathrm{~mL}\right)$, which was then stirred vigorously for 20 minutes. A light brown precipitate was collected and washed with distilled water. Recrystallisation from isopropyl alcohol afforded the title compound (1.05 g, $1.8 \mathrm{mmol}, 66 \%)$ as colourless crystals; $\mathrm{mp} 96-97{ }^{\circ} \mathrm{C}$ (from isopropyl alcohol); (Found: C, 57.5; H, 4.9; N, 7.1. $\mathrm{C}_{28} \mathrm{H}_{29} \mathrm{Br}_{2} \mathrm{~N}_{3} \mathrm{O}$ requires C, 57.7; H, 5.0; N, 7.2\%); $\delta_{\mathrm{H}}(400$ $\left.\mathrm{MHz}, \mathrm{CDCl}_{3}\right) 0.87\left(3 \mathrm{H}, \mathrm{t}, J\right.$ 6.5, $\left.\mathrm{CH}_{3}\right), 1.22-1.50\left(10 \mathrm{H}, \mathrm{m}, \mathrm{CH}_{2}\right) 1.74-1.84\left(2 \mathrm{H}, \mathrm{m}, \mathrm{CH}_{2}\right), 3.98$ $\left(2 \mathrm{H}, \mathrm{t}, J\right.$ 6.5, $\left.\mathrm{CH}_{2}\right), 6.93(2 \mathrm{H}, \mathrm{d}, J$ 9.0, $\mathrm{ArH}), 7.04(2 \mathrm{H}, \mathrm{d}, J$ 9.0, $\mathrm{ArH}), 7.14(2 \mathrm{H}, \mathrm{dd}, J$ 8.0, 8.0, $\operatorname{Ar} H), 7.28(2 \mathrm{H}, \mathrm{d}, J$ 8.0, $\operatorname{Ar} H), 7.49(2 \mathrm{H}, \mathrm{d}, J$ 8.0, $\operatorname{Ar} H), 7.70(2 \mathrm{H}, \mathrm{s}, \operatorname{Ar} H) ; \delta_{\mathrm{C}}(100 \mathrm{MHz}$ $\left.\mathrm{CDCl}_{3}\right)$ 14.3, 22.8, 26.1, 29.2, 29.4, 29.5, 31.9, 68.7, 116.0, 122.7, 126.7, 127.1, 128.7, 128.9, 130.0, 131.9, 132.9, 153.9, 160.3; m/z (ES) $582.0746\left([\mathrm{M}+\mathrm{H}]^{+} . \mathrm{C}_{28} \mathrm{H}_{30}{ }^{79} \mathrm{Br}_{2} \mathrm{~N}_{3} \mathrm{O}\right.$ requires 582.0756), (ES+) $647\left([\mathrm{M}+\mathrm{ACN}+\mathrm{Na}]^{+}, 12 \%\right), 584(100)$.

\section{General procedure for Suzuki polymerization - Method A}

A multi-neck round bottomed flask was charged with 3,6-bis(4,4,5,5-tetramethyl-1,3,2dioxaborolane-2-yl)-9,9-dioctyldibenzosilole (550 $\mathrm{mg}, 0.8 \mathrm{mmol}$ ), the chosen co-monomer (0.8 mmol), palladium(II)acetate $(4 \mathrm{mg}, 17 \mu \mathrm{mol})$ and toluene $(20 \mathrm{~mL})$. The mixture was stirred and degassed with nitrogen for 20 minutes. Tricyclohexylphosphonium 
Keyworth et al., 'The tuning of the energy levels of dibenzosilole copolymers....'

tetrafluoroborate $(25 \mathrm{mg}, 69 \mu \mathrm{mol})$ and a degassed $20 \%$ aqueous solution of tetraethylammonium hydroxide $(2 \mathrm{~mL})$ were added under nitrogen. The reaction mixture was degassed for a further 10 minutes, then stirred at $110{ }^{\circ} \mathrm{C}$ for 48 hours, and finally allowed to cool to $25{ }^{\circ} \mathrm{C}$. Bromobenzene $(0.09 \mathrm{~mL}, 0.8 \mathrm{mmol})$, palladium(II)acetate $(4 \mathrm{mg}, 17 \mu \mathrm{mol})$ and tricyclohexylphosphonium tetrafluoroborate $(25 \mathrm{mg}, 69 \mu \mathrm{mol})$ were added under nitrogen. The mixture was stirred and degassed with nitrogen for 10 minutes, after which the reaction was stirred at $110{ }^{\circ} \mathrm{C}$ for $20 \mathrm{~h}$ and then allowed to cool to $25^{\circ} \mathrm{C}$. Phenylboronic acid (204 mg, $1.7 \mathrm{mmol}$ ), palladium(II)acetate (4 mg, $17 \mu \mathrm{mol})$ and tricyclohexylphosphonium tetrafluoroborate $(25 \mathrm{mg}, 69 \mu \mathrm{mol})$ were added under nitrogen. The mixture was stirred and degassed with nitrogen for 10 minutes, after which the reaction was stirred at $110{ }^{\circ} \mathrm{C}$ for $20 \mathrm{~h}$. The reaction was allowed to cool to room temperature. The organic layer was removed and filtered though a pad of silica. The solution was concentrated under vacuum, then added dropwise into a vigorously stirred flask of methanol $(500 \mathrm{~mL})$. The resulting precipitate was filtered and collected, then re-dissolved in methylene chloride and filtered through a plug of silica. The solution was again concentrated under vacuum and precipitated into a vigorously stirred flask of methanol $(500 \mathrm{~mL})$. The precipitate was filtered, washed with methanol and dried in vacuo to afford copolymer P1-P4.

\section{General procedure for Suzuki polymerization - Method B}

A multi-neck round bottomed flask was charged with 2,7-bis(4,4,5,5-tetramethyl-1,3,2dioxaborolane-2-yl)-9,9-dioctyldibenzosilole (1.00 g, $1.5 \mathrm{mmol})$, the chosen co-monomer (1.5 mmol), palladium(II)acetate $(7 \mathrm{mg}, 31 \mu \mathrm{mol})$ and toluene $(30 \mathrm{~mL})$. The remaining procedure was as per method A, but using the following quantities: stage 1 tricyclohexylphosphonium tetrafluoroborate (46 mg, $125 \mu \mathrm{mol}$ ), tetraethylammonium hydroxide $(20 \%, 3 \mathrm{~mL})$; stage 2 - bromobenzene $(0.16 \mathrm{~mL}, 1.5 \mathrm{mmol})$, palladium(II)acetate (7 mg, $31 \mu \mathrm{mol})$, tricyclohexylphosphonium tetrafluoroborate (46 mg, $125 \mu \mathrm{mol}$ ); stage 3 - 
Keyworth et al., 'The tuning of the energy levels of dibenzosilole copolymers....'

phenylboronic acid (370 mg, $3.0 \mathrm{mmol}$ ), palladium(II)acetate (7 $\mathrm{mg}, 31 \mu \mathrm{mol})$, tricyclohexylphosphonium tetrafluoroborate (46 mg, $125 \mu \mathrm{mol})$. Precipitations: methanol (500 mL). Dried in vacuo to afford copolymer P5-P8.

\section{a, $\omega$-Diphenylpoly $(N$-octyl-9H-carbazole-3,6-diyl-9,9-dioctyl-9H-dibenzosilole-3,6-}

diyl) (P1). 3,6-Dibromo- $N$-octyl-9H-carbazole $(365 \mathrm{mg}, 0.8 \mathrm{mmol})$ was used as the comonomer, following general polymerisation method A, to afford the title compound (547 mg, 96\%) as a yellow granulated, fibrous solid. (Found: C, 84.2; H, 9.5; N, 1.95. A repeat unit composition of $\mathrm{C}_{48} \mathrm{H}_{63} \mathrm{NSi}$ requires: $\mathrm{C}, 84.3 ; \mathrm{H}, 9.6 ; \mathrm{N}, 2.05 \%$ ); GPC in THF vs. narrow polystyrene standards revealed $M_{\mathrm{w}}=6600, M_{\mathrm{n}}=4800, \mathrm{PDI}=1.38 ; M_{\mathrm{w}}=1600, M_{\mathrm{n}}=1500$, PDI $=1.06 ; \lambda_{\max } / \mathrm{nm}\left(\mathrm{CHCl}_{3}\right.$ solution) $296 ; \delta_{\mathrm{H}}\left(400 \mathrm{MHz}, \mathrm{CDCl}_{3}\right)$ 0.73-0.88 (br m, $\mathrm{CH}_{2}$ and $\mathrm{CH}_{3}$ ), 0.94-1.05 (br m, $\mathrm{CH}_{2}$ ), 1.09-1.42 (br m, $\mathrm{CH}_{2}$ ), 1.42-1.54 (br m, $\mathrm{CH}_{2}$ ), 1.79-1.88 (br m, $\mathrm{CH}_{2}$ ), 3.95-4.05 (br m, $\mathrm{CH}_{2}$ ), 6.93-7.04 (m, $\mathrm{ArH}$ ), 7.10-7.26 (br m, ArH), 7.27-7.54 (br m, $\operatorname{Ar} H), 7.62-7.96($ br m, $\operatorname{Ar} H), 8.04(\mathrm{~s}, \mathrm{Ar} H) ; \delta_{\mathrm{C}}\left(100 \mathrm{MHz}, \mathrm{CDCl}_{3}\right)$ 1.2, 12.5, 12.7, 14.3, 22.9, $24.2,24.3,25.1,27.5,29.4,32.1,33.7,109.3,119.4,120.2,123.7,126.8,133.9,134.9,136.2$, $140.7,141.9,144.2,144.3,149.3$.

\section{$\alpha, \omega$-Diphenylpoly(9,9-dioctyl-9H-dibenzosilole-3,6-diyl-2,5-bis( $m$-phenylene)-1,3,5-}

oxadiazole) (P2). 2,5-Bis(3-bromophenyl)-1,3,4-oxadiazole (317 mg, $0.8 \mathrm{mmol}$ ) was used as the co-monomer, following general polymerisation method A, to afford the title compound (464 mg, 89\%) as an off-white powder. (Found: C, 80.35; H, 7.8; N, 4.4. A repeat unit composition of $\mathrm{C}_{42} \mathrm{H}_{50} \mathrm{~N}_{2} \mathrm{OSi}$ requires: $\mathrm{C}, 80.5 ; \mathrm{H}, 8.0 ; \mathrm{N}, 4.5 \%$ ); GPC assay in THF vs. narrow polystyrene standards revealed $M_{\mathrm{w}}=5600, M_{\mathrm{n}}=3300, \mathrm{PDI}=1.70 ; \lambda_{\max } / \mathrm{nm}\left(\mathrm{CHCl}_{3}\right.$ solution) 268; $\delta_{\mathrm{H}}\left(400 \mathrm{MHz}, \mathrm{CDCl}_{3}\right)$ 0.51-1.43 (br m, $\mathrm{CH}_{2}$ and $\mathrm{CH}_{3}$ ), 1.72 (br s, $\mathrm{CH}_{2}$ ), 7.317.93 (br m, $\mathrm{ArH}$ ), 8.02-8.21 (br m, $\mathrm{ArH}$ ), 8.21-8.51 (br m, $\mathrm{ArH}) ; \delta_{\mathrm{C}}\left(100 \mathrm{MHz}, \mathrm{CDCl}_{3}\right)$ 22.8, 
Keyworth et al., 'The tuning of the energy levels of dibenzosilole copolymers....'

$23.3,24.2,29.3,29.4,32.1,33.6,120.1,124.6,125.8,126.1,126.9,128.4,129.0,129.8$, 134.1, 142.1, 149.0, 164.9.

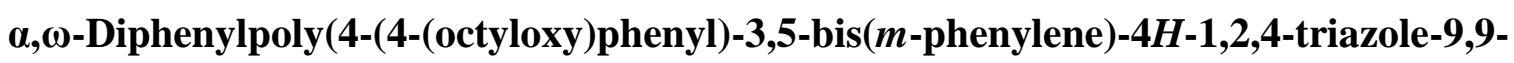
dioctyl-9H-dibenzosilole-3,6-diyl) (P3). 4-(4-(Octyloxy)phenyl)-3,5-bis(3-bromophenyl)$4 H$-1,2,4-triazole (487 $\mathrm{mg}, 0.8 \mathrm{mmol}$ ) was used as the co-monomer, following general polymerisation method $\mathrm{A}$, to afford the title compound (650 $\mathrm{mg}, 94 \%)$ as a light yellow fibrous powder. GPC assay in THF vs. narrow polystyrene standards revealed $M_{\mathrm{w}}=10500$, $M_{\mathrm{n}}=6900, \mathrm{PDI}=1.52 ; M_{\mathrm{w}}=1800, M_{\mathrm{n}}=1700, \mathrm{PDI}=1.05 ; \delta_{\mathrm{H}}\left(400 \mathrm{MHz}, \mathrm{CDCl}_{3}\right) 0.74-1.01$ (br m, $\mathrm{CH}_{2}$ and $\mathrm{CH}_{3}$ ), 1.01-1.45 (br m, $\mathrm{CH}_{2}$ ), 1.58-1.81 (br m, $\mathrm{CH}_{2}$ ), 3.71-3.98 (br m, $\mathrm{CH}_{2}$ ), 6.71-7.02 (br m, $\mathrm{ArH}$ ), 7.02-7.81 (br m, $\mathrm{ArH}$ ), 8.03-8.62 (br m, $\mathrm{ArH}$ ); $\delta_{\mathrm{C}}\left(100 \mathrm{MHz}, \mathrm{CDCl}_{3}\right.$ ) $12.6,14.3,22.8,24.2,25.1,26.3,29.3,29.4,32.0,33.7,68.7,116.0,119.9,126.6,127.2$, $127.5,127.8,127.9,128.1,128.2,129.0,129.1,129.3,133.8,137.7,141.9,142.2,149.0$.

\section{$\alpha, \omega$-Diphenylpoly(bis(p-phenylene)-4-sec-butylphenylamine-9,9-dioctyl-9H-}

dibenzosilole-3,6-diyl) (P4). Bis(4-bromophenyl)-4-sec-butylphenylamine (383 mg, 0.8 mmol) was used as the co-monomer, following general polymerisation method A, to afford the title compound (541 mg, 92\%) as a light yellow granulated solid. (Found: C, 84.9; H, 9.0; $\mathrm{N}$, 1.9. A repeat unit composition of $\mathrm{C}_{50} \mathrm{H}_{61} \mathrm{NSi}$ requires: $\mathrm{C}, 85.05 ; \mathrm{H}, 9.0 ; \mathrm{N}, 2.0 \%$ ); GPC assay in THF vs. narrow polystyrene standards revealed $M_{\mathrm{w}}=10700, M_{\mathrm{n}}=8000, \mathrm{PDI}=1.34$; $M_{\mathrm{w}}=2400, M_{\mathrm{n}}=2100, \mathrm{PDI}=1.11 ; \lambda_{\max } / \mathrm{nm}\left(\mathrm{CHCl}_{3}\right.$ solution $) 353 ; \delta_{\mathrm{H}}\left(400 \mathrm{MHz}, \mathrm{CDCl}_{3}\right)$ 0.78-0.90 (m, $\mathrm{CH}_{2}$ and $\mathrm{CH}_{3}$ ), 0.92-1.01 (br m, $\mathrm{CH}_{2}$ ), 1.11-1.33 (br m, $\mathrm{CH}_{2}$ ), 1.33 (s, $\mathrm{CH}_{3}$ ), 1.33-1.47 (br m, $\mathrm{CH}_{2}$ ), 1.51-1.63 (br m, $\mathrm{CH}_{2}$ ), 2.30-2.62 (br m, $\mathrm{CH}$ ), 6.95-7.26 (m, $\mathrm{ArH}$ ), 7.29-7.69 (m, $\operatorname{ArH}), 7.77-7.82(\mathrm{~m}, \mathrm{Ar} H), 8.08$ (br s, $\mathrm{Ar} H) ; \delta_{\mathrm{C}}\left(100 \mathrm{MHz}, \mathrm{CDCl}_{3}\right)$ 12.5, 12.7, $14.3,22.0,22.9,24.3,25.1,29.4,31.5,32.1,33.7,41.3,119.4,123.9,125.2,125.3,127.9$, $128.2,133.8,135.0,136.7,142.8,143.3,144.9,145.3,147.5,149.1$. 
Keyworth et al., 'The tuning of the energy levels of dibenzosilole copolymers....'

$\alpha, \omega$-Diphenylpoly $(N$-octyl-9H-carbazole-3,6-diyl-9,9-dioctyl-9H-dibenzosilole-2,7-

diyl) (P5). 3,6-Dibromo- $N$-octyl-9H-carbazole $(365 \mathrm{mg}, 0.8 \mathrm{mmol})$ was used as the comonomer, following general polymerisation method B, to afford the title compound (994 mg, 96\%) as a yellow granulated solid. GPC assay in THF vs. narrow polystyrene standards revealed $M_{\mathrm{w}}=5500, M_{\mathrm{n}}=3400, \mathrm{PDI}=1.61 ; \lambda_{\max } / \mathrm{nm}\left(\mathrm{CHCl}_{3}\right.$ solution $) 353 ; \delta_{\mathrm{H}}(400 \mathrm{MHz}$, $\mathrm{CDCl}_{3}$ ) 0.75-0.90 (m, $\mathrm{CH}_{2}$ and $\mathrm{CH}_{3}$ ), 0.95-1.12 (br m, $\mathrm{CH}_{2}$ ), 1.12-1.55 (br m, $\mathrm{CH}_{2}$ ), 1.832.02 (br m, $\mathrm{CH}_{2}$ ), 4.20-4.42 (br m, $\mathrm{CH}_{2}$ ), 7.32-7.56 (m, $\mathrm{ArH}$ ), 7.73-8.01 (m, $\mathrm{ArH}$ ), 8.43-8.49 $(\mathrm{m}, \mathrm{Ar} H) ; \delta_{\mathrm{C}}\left(100 \mathrm{MHz}, \mathrm{CDCl}_{3}\right)$ 12.7, 14.3, 22.9, 24.2, 25.1, 25.9, 27.6, 29.4, 29.6, 32.1, 33.7, $119.1,121.4,123.8,125.6,127.9,129.3,131.5,132.8,135.0,137.0,138.9,140.6$.

$\alpha, \omega$-Diphenylpoly(9,9-dioctyl-9H-dibenzosilole-2,7-diyl-2,5-bis(m-phenylene)-1,3,5-

oxadiazole) (P6). 2,5-Bis(3-bromophenyl)-1,3,4-oxadiazole (577 mg, $1.5 \mathrm{mmol}$ ) was used as the co-monomer, following general polymerisation method $\mathrm{B}$, to afford the title compound (863 mg, 88\%) as a white fibrous solid. (Found: C, 80.4; H, 7.9; N, 4.4. Repeat unit composition of $\mathrm{C}_{42} \mathrm{H}_{50} \mathrm{~N}_{2} \mathrm{OSi}$ requires: $\mathrm{C}, 80.5 ; \mathrm{H}, 8.0 ; \mathrm{N}, 4.5 \%$ ); GPC assay in THF vs. narrow polystyrene standards revealed $M_{\mathrm{w}}=4700, M_{\mathrm{n}}=4000, \mathrm{PDI}=1.19 ; M_{\mathrm{w}}=1800, M_{\mathrm{n}}=$ $1700, \mathrm{PDI}=1.04 ; M_{\mathrm{w}}=700, M_{\mathrm{n}}=600, M_{\mathrm{P}}=1100, \mathrm{PDI}=1.22 ; \lambda_{\max } / \mathrm{nm}\left(\mathrm{CHCl}_{3}\right.$ solution $)$ $320 ; \delta_{\mathrm{H}}\left(400 \mathrm{MHz}, \mathrm{CDCl}_{3}\right)$ 0.75-0.81 (m, $\mathrm{CH}_{2}$ and $\left.\mathrm{CH}_{3}\right), 0.81-1.37$ (br m, $\mathrm{CH}_{2}$ ), 1.37 (s, $\mathrm{CH}_{3}$ ), 1.37-1.49 (br m, $\mathrm{CH}_{2}$ ), 1.62 (br s, $\mathrm{CH}_{2}$ ), 7.30-7.54 (m, $\mathrm{ArH}$ ), 7.60-7.72 (br m, ArH), 7.72-8.02 (br m, ArH), 8.06-8.21 (br m, ArH), 8.31 (br s, $\operatorname{Ar} H$ ), 8.38-8.52 (br m, ArH); $\delta_{\mathrm{C}}\left(100 \mathrm{MHz}, \mathrm{CDCl}_{3}\right)$ 12.3, 14.1, 22.6, 24.0, 24.9, 29.1, 29.2. 31.8, 33.4, 121.4, 121.6, 124.2, $124.5,125.6,125.6,127.1,127.3,129.3,129.6,129.8,130.5,130.6,132.0$.

$\alpha, \omega$-Diphenylpoly(4-(4-(octyloxy)phenyl)-3,5-bis( $m$-phenylene)-4H-1,2,4-triazole-9,9dioctyl-9H-dibenzosilole-2,7-diyl) (P7). 4-(4-(Octyloxy)phenyl)-3,5-bis(3-bromophenyl)$4 H$-1,2,4-triazole $(886 \mathrm{mg}, 1.5 \mathrm{mmol})$ was used as the co-monomer, following general 
Keyworth et al., 'The tuning of the energy levels of dibenzosilole copolymers....'

polymerisation method $\mathrm{B}$, to afford the title compound $(1.14 \mathrm{~g}, 91 \%)$ as a light yellow fibrous solid. (Found: $\mathrm{C}, 80.9 ; \mathrm{H}, 8.5 ; \mathrm{N}, 4.9$. A repeat unit composition of $\mathrm{C}_{56} \mathrm{H}_{69} \mathrm{~N}_{3} \mathrm{OSi}$ requires: $\mathrm{C}$, 81.0; $\mathrm{H}, 8.6 ; \mathrm{N}, 5.1 \%$ ); GPC assay in THF vs. narrow polystyrene standards revealed $M_{\mathrm{w}}=$ $12200, M_{\mathrm{n}}=6700, \mathrm{PDI}=1.82 ; \lambda_{\max } / \mathrm{nm}\left(\mathrm{CHCl}_{3}\right.$ solution $) 326 ; \delta_{\mathrm{H}}\left(400 \mathrm{MHz}, \mathrm{CDCl}_{3}\right) 0.73-$ 0.89 (m, $\mathrm{CH}_{2}$ and $\mathrm{CH}_{3}$ ), 1.10-1.39 (br m, $\mathrm{CH}_{2}$ ), 1.41-1.52 (br m, $\mathrm{CH}_{2}$ ), 1.79-1.84 (br m, $\mathrm{CH}_{2}$ ), 3.96-4.09 (br m, $\mathrm{CH}_{2}$ ), 6.95-7.04 (br m, ArH), 7.32-7.53 (br m, ArH), 7.64-7.90 (br m, ArH), 7.92 (br s, $\mathrm{Ar} H) ; \delta_{\mathrm{C}}\left(100 \mathrm{MHz}, \mathrm{CDCl}_{3}\right)$ 12.5, 14.3, 22.8, 24.1, 26.3, 29.3, 29.4, 29.6, 32.0, $33.6,116.0,121.5,127.5,127.6,128.0,129.1,129.2,131.9,138.9,139.2,141.7,147.7$, 155.0, 160.3.

\section{a, $\omega$-Diphenylpoly(bis( $p$-phenylene)-4-sec-butylphenylamine-9,9-dioctyl-9H-}

dibenzosilole-2,7-diyl) (P8). Bis(4-bromophenyl)-4-sec-butylphenylamine (697 mg, 1.5 mmol) was used as the co-monomer, following general polymerisation method $\mathrm{B}$, to afford the title compound $(0.98 \mathrm{~g}, 92 \%)$ as a bright yellow fibrous solid. GPC assay in THF vs. narrow polystyrene standards revealed $M_{\mathrm{w}}=11700, M_{\mathrm{n}}=5700, \mathrm{PDI}=2.05 ; \lambda_{\max } / \mathrm{nm}\left(\mathrm{CHCl}_{3}\right.$ solution) 390; $\delta_{\mathrm{H}}\left(400 \mathrm{MHz}, \mathrm{CDCl}_{3}\right)$ 0.78-0.90 (m, $\mathrm{CH}_{2}$ and $\left.\mathrm{CH}_{3}\right), 0.93-1.03$ (br m, $\mathrm{CH}_{2}$ ), 1.13-1.47 (br m, $\mathrm{CH}_{2}$ ), 1.54-1.64 (m, $\mathrm{CH}_{2}$ ), 2.52-2.63 (m, $\left.\mathrm{CH}\right), 6.95-7.26$ (m, ArH), 7.51$7.68(\mathrm{~m}, \mathrm{ArH}), 7.78-7.92(\mathrm{~m}, \mathrm{ArH}), 8.04(\mathrm{~s}, \mathrm{Ar} H) ; \delta_{\mathrm{C}}\left(100 \mathrm{MHz}, \mathrm{CDCl}_{3}\right)$ 1.2, 12.6, 14.3, 22.0, $22.9,24.2,25.1,29.3,29.5,31.5,32.1,33.6,41.3,121.4,124.0,125.1,127.8,127.9,128.1$, $128.2,128.7,131.6,132.3,135.3,138.9,139.4,147.1,147.3$.

\section{References}

1. J. H. Burroughes, D. D. C. Bradley, A. R. Brown, R. N. Marks, K. Mackay, R. H. Friend, P. L. Burn and A. B. Holmes, Nature, 1990, 347, 539-541.

2. A. Kraft, A. C. Grimsdale and A. B. Holmes, Angew. Chem. Int. Ed., 1998, 37, 402428. 
Keyworth et al., 'The tuning of the energy levels of dibenzosilole copolymers....'

3. R. H. Friend, R. W. Gymer, A. B. Holmes, J. H. Burroughes, R. N. Marks, C. Taliani, D. D. C. Bradley, D. A. Dos Santos, J. L. Bredas, M. Logdlund and W. R. Salaneck, Nature, 1999, 397, 121-128.

4. U. Mitschke and P. Bauerle, J. Mater. Chem., 2000, 10, 1471-1507.

5. M.-C. Choi, Y. Kim and C.-S. Ha, Prog. Polym. Sci., 2008, 33, 581-630.

6. A. C. Grimsdale, K. Leok Chan, R. E. Martin, P. G. Jokisz and A. B. Holmes, Chem. Rev., 2009, 109, 897-1091.

7. K. Müllen and U. Scherf, Organic Light-Emitting Devices: Synthesis, Properties and Applications, Wiley-VCH: Weinheim, 2006.

8. J. Chen and Y. Cao, Macromol. Rapid Commun., 2007, 28, 1714-1742.

9. W. W. H. Wong, J. F. Hooper and A. B. Holmes, Aust. J. Chem., 2009, 62, 393-401.

10. P.-L. T. Boudreault, S. Beaupre and M. Leclerc, Polymer Chemistry, 2010, 1, $127-$ 136.

11. Q. Zhao, S.-J. Liu and W. Huang, Macromol. Chem. Phys., 2009, 210, 1580-1590.

12. A. C. Arias, J. D. MacKenzie, I. McCulloch, J. Rivnay and A. Salleo, Chem. Rev., 2010, 110, 3-24.

13. Y. Yoshiro, Science and Technology of Advanced Materials, 2009, 10, 024313.

14. I. McCulloch, M. Heeney, M. L. Chabinyc, D. DeLongchamp, R. J. Kline, M. Cölle, W. Duffy, D. Fischer, D. Gundlach, B. Hamadani, R. Hamilton, L. Richter, A. Salleo, M. Shkunov, D. Sparrowe, S. Tierney and W. Zhang, Adv. Mater., 2009, 21, 10911109.

15. S. Beaupré, P.-L. T. Boudreault and M. Leclerc, Adv. Mater., 2010, 22, E6-E27.

16. J. C. Sanchez and W. C. Trogler, J. Mater. Chem., 2008, 18, 3143-3156.

17. M. Sims, D. D. C. Bradley, M. Ariu, M. Koeberg, A. Asimakis, M. Grell and D. G. Lidzey, Adv. Funct. Mater., 2004, 14, 765-781.

18. K. Becker, J. M. Lupton, J. Feldmann, B. S. Nehls, F. Galbrecht, D. Q. Gao and U. Scherf, Adv. Funct. Mater., 2006, 16, 364-370.

19. V. N. Bliznyuk, S. A. Carter, J. C. Scott, G. Klarner, R. D. Miller and D. C. Miller, Macromolecules, 1999, 32, 361-369.

20. K. L. Chan, M. Sims, S. I. Pascu, M. Ariu, A. B. Holmes and D. D. C. Bradley, Adv. Funct. Mater., 2009, 19, 2147-2151.

21. J. Chen and Y. Cao, Accounts Chem. Res., 2009, 42, 1709-1718.

22. S. Yamaguchi and K. Tamao, J. Chem. Soc., Dalton Trans., 1998, 3693-3702.

23. M. Hissler, P. W. Dyer and R. Réau, Coordin. Chem. Rev., 2003, 244, 1-44.

24. K. L. Chan, M. J. McKiernan, C. R. Towns and A. B. Holmes, J. Am. Chem. Soc., 2005, 127, 7662-7663.

25. P.-L. T. Boudreault, A. Michaud and M. Leclerc, Macromol. Rapid Commun., 2007, 28, 2176-2179.

26. E. Wang, L. Wang, L. Lan, C. Luo, W. Zhuang, J. Peng and Y. Cao, Appl. Phys. Lett., 2008, 92, 033307-033303.

27. H. Usta, G. Lu, A. Facchetti and T. J. Marks, J. Am. Chem. Soc., 2006, 128, 90349035.

28. G. Lu, H. Usta, C. Risko, L. Wang, A. Facchetti, M. A. Ratner and T. J. Marks, J. Am. Chem. Soc., 2008, 130, 7670-7685.

29. J. C. Sanchez, A. G. DiPasquale, A. L. Rheingold and W. C. Trogler, Chem. Mater., 2007, 19, 6459-6470.

30. J. C. Sanchez, S. A. Urbas, S. J. Toal, A. G. DiPasquale, A. L. Rheingold and W. C. Trogler, Macromolecules, 2008, 41, 1237-1245.

31. K. L. Chan, S. E. Watkins, C. S. K. Mak, M. J. McKiernan, C. R. Towns, S. I. Pascu and A. B. Holmes, Chem. Commun., 2005, 5766-5768. 
Keyworth et al., 'The tuning of the energy levels of dibenzosilole copolymers....'

32. Y. Q. Mo, R. Y. Tian, W. Shi and Y. Cao, Chem. Commun., 2005, 4925-4926.

33. E. G. Wang, C. Li, Y. Q. Mo, Y. Zhang, G. Ma, W. Shi, J. B. Peng, W. Yang and Y. Cao, J. Mater. Chem., 2006, 16, 4133-4140.

34. Y.-Q. Mo, X.-Y. Deng, X. Jiang and Q.-H. Cui, J. Polym. Sci., Part A: Polym. Chem., 2009, 47, 3286-3295.

35. L. Li, C. Xu and S. Li, Tetrahedron Lett., 2010, 51, 622-624.

36. C. Duan, W. Cai, F. Huang, J. Zhang, M. Wang, T. Yang, C. Zhong, X. Gong and Y. Cao, Macromolecules, 2010, 43, 5262-5268.

37. L. Huo, H.-Y. Chen, J. Hou, T. L. Chen and Y. Yang, Chem. Commun., 2009, 55705572.

38. J. Hou, H.-Y. Chen, S. Zhang, G. Li and Y. Yang, J. Am. Chem. Soc., 2008, 130, 16144-16145.

39. J. Ohshita, Y. Kurushima, K.-H. Lee, A. Kunai, Y. Ooyama and Y. Harima, Organometallics, 2007, 26, 6591-6595.

40. S. Oyston, C. Wang, G. Hughes, A. S. Batsanov, I. F. Perepichka, M. R. Bryce, J. H. Ahn, C. Pearson and M. C. Petty, J. Mater. Chem., 2005, 15, 194-203.

41. E. Jansson, P. Chandra Jha and H. Agren, Chem. Phys., 2006, 330, 166-171.

42. J. Kido, K. Hongawa, K. Okuyama and K. Nagai, Appl. Phys. Lett., 1993, 63, $2627-$ 2629.

43. C. W. Tang and S. A. VanSlyke, Appl. Phys. Lett., 1987, 51, 913-915.

44. S. Liu, X. Jiang, H. Ma, M. S. Liu and A. K. Y. Jen, Macromolecules, 2000, 33, 35143517.

45. K. Brunner, A. van Dijken, H. Borner, J. J. A. M. Bastiaansen, N. M. M. Kiggen and B. M. W. Langeveld, J. Am. Chem. Soc., 2004, 126, 6035-6042.

46. F. Monnier and M. Taillefer, Angew. Chem. Int. Ed., 2009, 48, 6954-6971.

47. H. B. Goodbrand and N.-X. Hu, J. Org. Chem., 1999, 64, 670-674.

48. $\quad$ R. Stolle and R. Stolle, Prakt. Chem., 1906, 73, 288-289.

49. S. M. Zain, R. Hashim, A. G. Taylor and D. Phillips, J. Mol. Struct., 1997, 401, 287300.

50. M. Thelakkat and H.-W. Schmidt, Adv. Mater., 1998, 10, 219-223.

51. K. N. Winzenberg, P. Kemppinen, G. Fanchini, M. Bown, G. E. Collis, C. M. Forsyth, K. Hegedus, T. B. Singh and S. E. Watkins, Chem. Mater., 2009, 21, 57015703.

52. J. M. Leger, S. A. Carter, B. Ruhstaller, H. G. Nothofer, U. Scherf, H. Tillman and H. H. Hörhold, Phys. Rev. B, 2003, 68, 54209-54215.

53. J. Lee, N. Chopra and F. So, Appl. Phys. Lett., 2008, 92, 33303-33306.

54. M. C. Gather, R. Alle, H. Becker and K. Meerholz, Adv. Mater., 2007, 19, 4460-4465.

55. H. Sirringhaus, N. Tessler and R. H. Friend, Science, 1998, 280, 1741-1744.

56. J. Zaumseil and H. Sirringhaus, Chem Rev, 2007, 107, 1296-1323.

57. T. K. Dougherty, K. S. Y. Lau and F. L. Hedberg, J. Org. Chem., 1983, 48, 52735280. 